Universidad de Lima

Facultad de Comunicación

Carrera de Psicología

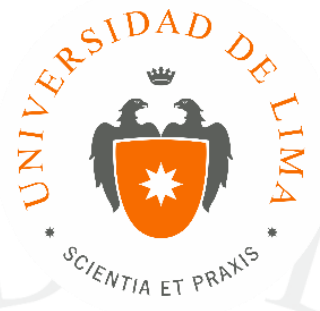

\title{
PERCEPCIONES DE LOS TRABAJADORES DE UNA EMPRESA PRIVADA DE LIMA METROPOLITANA ACERCA DEL CLIMA LABORAL Y BURNOUT
}

Tesis para optar el título profesional en Psicología

Ximena Pesaque Pasini

Código 20102067

Asesora

María del Carmen Espinoza Reyes

Lima - Perú

Setiembre de 2016 


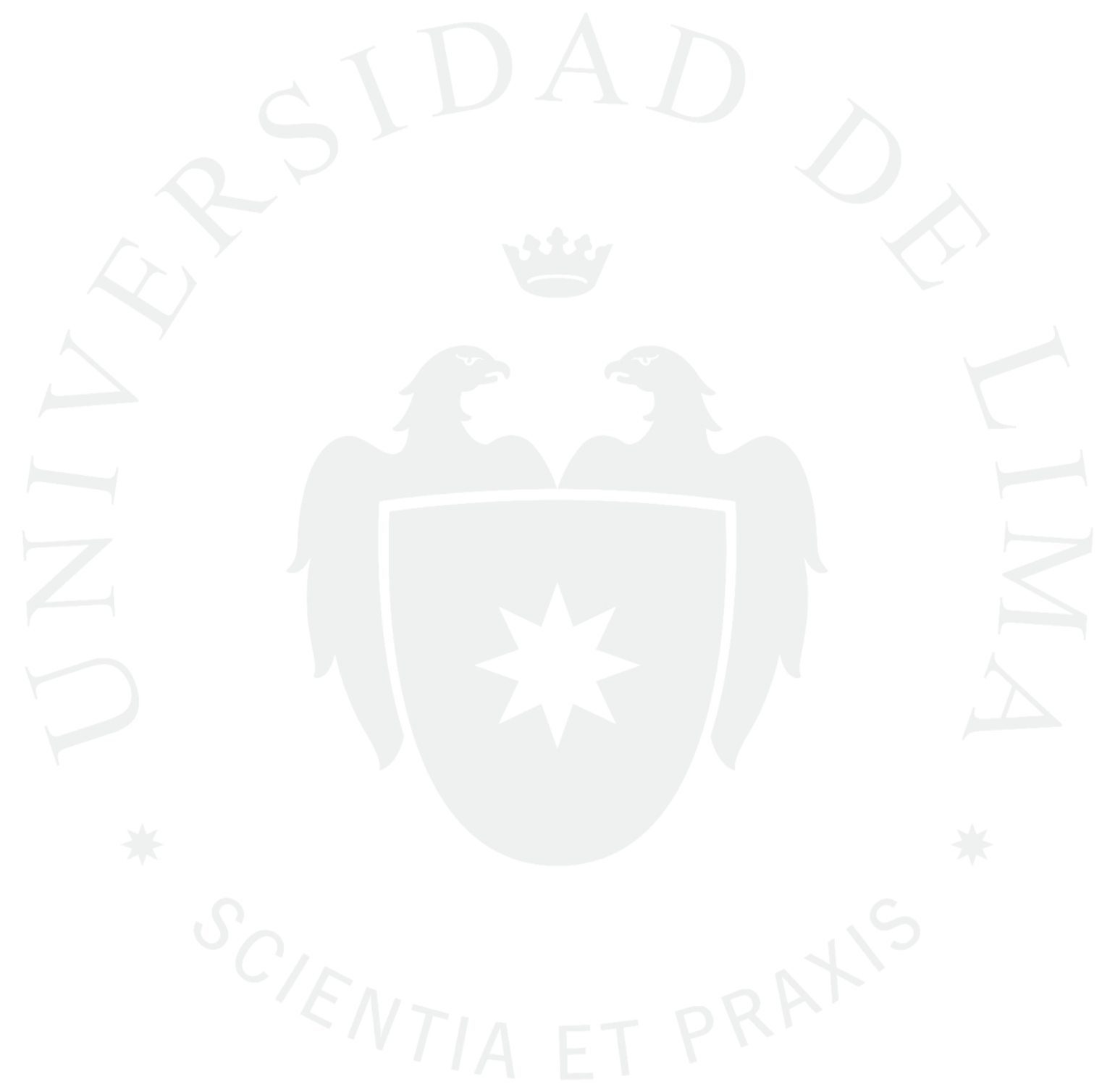




\section{PERCEPCIONES DE LOS TRABAJADORES DE UNA EMPRESA PRIVADA DE LIMA METROPOLITANA ACERCA DEL CLIMA LABORAL Y BURNOUT}




\section{TABLA DE CONTENIDOS}

CAPÍTULO I: PLANTEAMIENTO DEL PROBLEMA ........................................

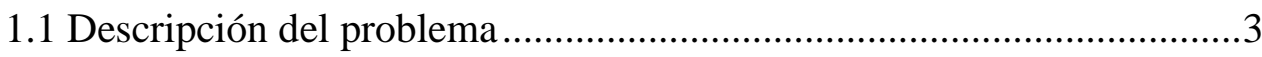

1.2 Justificación y relevancia............................................................... 6

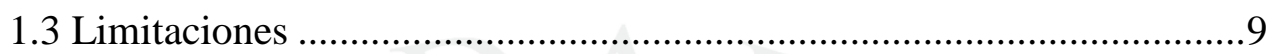

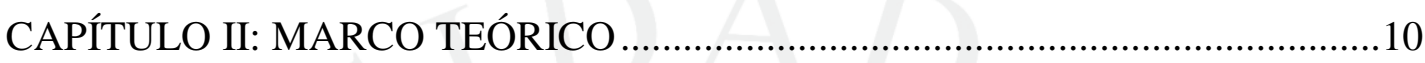

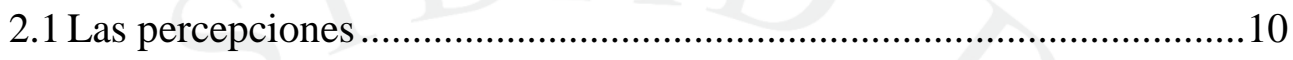

2.2 El clima laboral ...................................................................... 12

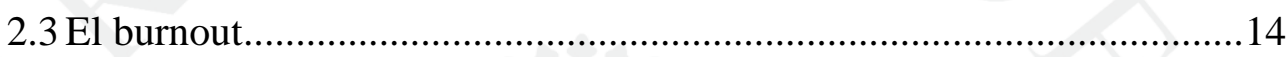

2.4 Relación del burnout y clima laboral .................................................17

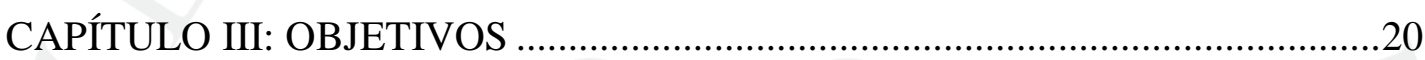

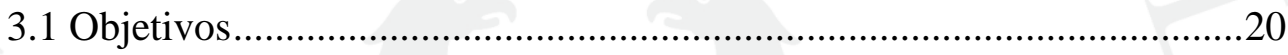

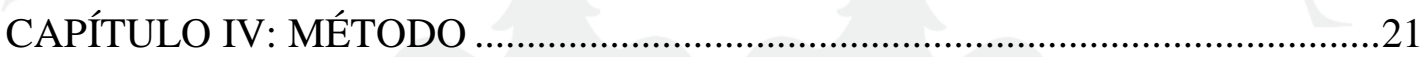

4.1 Tipo y diseño de investigación ......................................................21

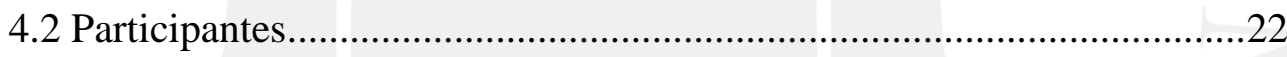

4.3 Técnicas de recolección de datos......................................................24

4.4 Procedimiento de recolección de datos ...............................................27

4.5 Estrategias de análisis de datos .....................................................28

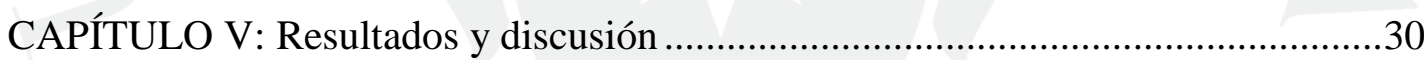

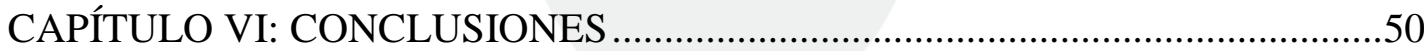

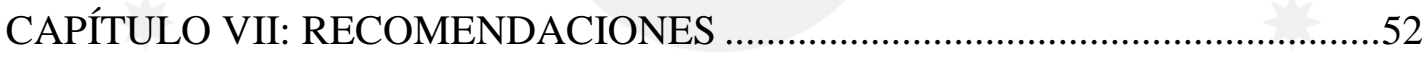

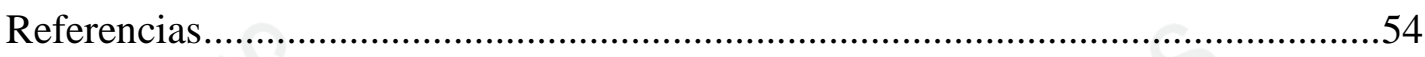

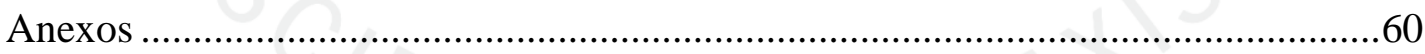




\section{ÍNDICE DE ANEXOS}

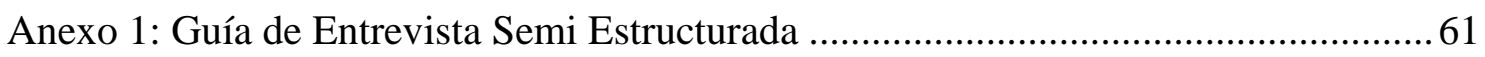

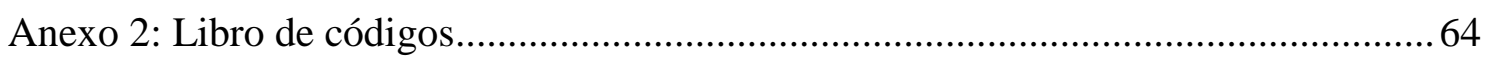

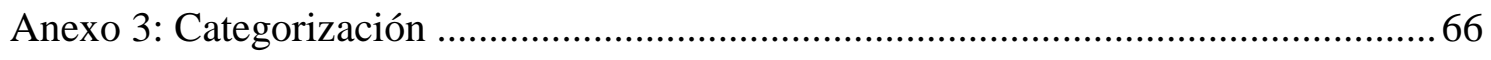

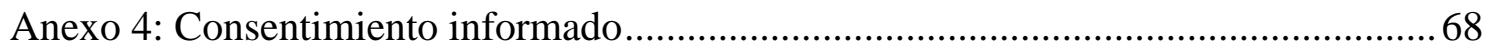




\section{RESUMEN}

El clima laboral como factor intrínseco en toda organización, ya sea grande o pequeña, tiene un impacto significativo tanto en el comportamiento como en el rendimiento de cada uno de sus colaboradores. Es por esta razón que, en los últimos años, el clima laboral y el burnout se han vuelto unos de los constructos más estudiados e investigados con la finalidad de conocer sus implicancias y minimizar las consecuencias negativas que producen estos factores dentro de las organizaciones. En este sentido, el presente estudio es una síntesis de la investigación con enfoque cualitativo, acerca de las percepciones sobre clima laboral y burnout de los trabajadores de una empresa privada de Lima Metropolitana.

Los objetivos de este estudio son: describir las percepciones de los trabajadores sobre los indicadores del síndrome de burnout y clima laboral en una empresa privada de Lima Metropolitana, identificar cómo están vinculadas las percepciones sobre el clima laboral y burnout de los trabajadores y, describir las características de la vinculación existente a partir de las percepciones de los trabajadores de la empresa sobre el clima laboral y burnout.

El estudio, de carácter exploratorio, siguió un diseño fenomenológico y utilizó como instrumento la entrevista semi estructurada, basada en el modelo dimensional del clima organizacional y en los indicadores de burnout. La entrevista se realizó a 10 trabajadores, con la finalidad de conocer sus percepciones sobre estos dos constructos.

Como resultados, se obtuvieron percepciones sobre el clima laboral y burnout que muestran que los trabajadores se encuentran satisfechos en la empresa donde laboran. Sin embargo, también se hallaron algunas opiniones negativas sobre la estructura organizacional, por lo cual se recomienda contar con organigramas y perfiles de puesto más estructurados para los trabajadores.

Palabras Clave: Percepciones, Clima Laboral, Burnout. 


\begin{abstract}
The work environment as an intrinsic factor in every organization whether big or small, has a significant impact on both behavior and performance of each of its employees. It is for this reason that in recent years the work environment and burnout have become one of the most studied construct with the purpose of knowing the implications and minimize the negative consequences caused by these factors within organizations. In this sense, the present study is a synthesis of research with qualitative approach about perceptions of burnout and work environment in workers of a private Chemical company of Lima.

The objectives of this study were: describe the perceptions of workers on indicators of burnout syndrome and work environment in a private chemical company in Metropolitan Lima, identify how they are linked to perceptions about work environment and burnout of workers and, describe the characteristics of the existing links from the perceptions of company workers on work environment and burnout.

The study is exploratory and phenomenological for this reason it was used a semistructured interview based on the dimensional model of work environment and indicators of burnout. The interview was conducted with 10 workers, in order to know their perceptions of these two factors.

As a result, the perceptions of the workers about work environment and burnout showing that workers are happy in the company. Although there are some negative views on the organizational structure, where it is recommended to have organizational charts and job profiles for workers.
\end{abstract}

Key words: perceptions, work environment, burnout. 


\section{CAPÍTULO I: PLANTEAMIENTO DEL PROBLEMA}

\subsection{Descripción del problema}

A lo largo de la historia, el trabajo se ha asentado como una necesidad del ser humano, donde los individuos se preparan gran parte de sus vidas para hacerlo y ejecutarlo de manera eficiente. Han surgido una gran cantidad de variables que se asocian directamente al rendimiento eficaz de los individuos, una de estas variables es el síndrome de burnout y el clima laboral.

El síndrome de burnout es conocido como el nivel máximo de estrés que puede padecer una persona, este síndrome afecta principalmente a personas que asisten a otras. Este síndrome está compuesto por tres factores principales, el primero es el agotamiento emocional, que es una sensación de desgaste físico donde se siente que no hay energía, el segundo es la despersonalización o alteración en las relaciones, que se entiende como un trato distante e indiferente a las personas que se tengan a cargo, y el tercero es la falta de realización personal, baja autoestima y sensación de fracaso profesional (Maslach y Jackson, 1981).

Una definición actualizada y ampliamente aceptada del término es la propuesta por Maslach, Schaufeli y Leiter (2001), quienes definen el burnout como, "una respuesta prolongada a estresores crónicos a nivel personal y relacional en el trabajo, determinado a partir de las dimensiones conocidas como agotamiento, cinismo e ineficacia profesional" (p. 397).

Por otro lado el clima laboral es un factor que está tomando valor en las empresas actuales como un indicador que aporta a la productividad y rendimiento de las empresas.

Evaluando el clima laboral se pueden determinar las dificultades que existen en una empresa a nivel de recursos humanos. El capital humano trabaja en la empresa para facilitar o dificultar los pasos que conducirán a la productividad de los mismos, y por ende de la organización (Maish, 2004).

No existen muchas investigaciones o estudios cualitativos sobre el clima laboral o el burnout, pero se pudieron hallar investigaciones cuantitativas que brindan aportes a la comprensión de estos fenómenos. 
Por ejemplo, existe una investigación realizada en Ecuador, donde se determinó que existe una relación entre el clima laboral y burnout. Si el docente en su ambiente laboral no se siente aceptado, escuchado o motivado, entonces se sentirá cansado y agotado del rol que está desempeñando. Por otro lado, se determinó que es importante evaluar el síndrome de burnout con frecuencia, para evitar que se propague y afecte al trabajo del docente de una manera grave (Villacís, 2015).

Con lo anterior puede verse como hay una asociación directa entre el burnout y el clima de las organizaciones, ya que con los factores anteriormente mencionados se ve la afección directa a la firmeza emocional y bienestar del individuo.

El burnout ha sido estudiado en hospitales y colegios, pero muy poco en empresas. Es importante poder estudiar el burnout en una empresa, ya que en todas las áreas se tienen muchos procedimientos y el núcleo es el servicio a los clientes, al igual que en los hospitales y colegios. El burnout es un factor importante para el bienestar de los trabajadores que se produce mayormente en áreas que dan soporte o servicio y que pueden afectar su vida cotidiana.

Tal punto de vista es compartido por Bianchi (1990), que afirma que por la naturaleza del trabajo hospitalario vinculado al cuidado de personas estando siempre presente el conflicto vida/muerte, aliado a las dificultades económicas y sociales de la categoría y de la sociedad, los profesionales se exponen a desarrollar el síndrome de burnout.

Para Pines y Aronson (1988) el burnout no está restringido a profesionales de ayuda, ya que lo consideraron como el estado de agotamiento mental, físico y emocional producido por la involucración crónica en el trabajo en situaciones emocionales demandantes. En esta misma línea, otros autores que han realizado numerosas investigaciones sobre esta temática (Gil-Monte y Peiró, 1997) lo definen como una respuesta al estrés laboral crónico integrado por actitudes y sentimientos negativos hacia las personas con las que se trabaja y hacia el propio rol profesional así como la vivencia de encontrase emocionalmente agotado. Esta respuesta se da en las profesiones de servicio pero no se limita sólo a ellas. El burnout se ha hecho muy popular a pesar de que no existe una claridad y precisión conceptual. No obstante, se puede reconocer una serie de características comunes en distintas definiciones revisadas, como señala Mingote (1998): predominan los síntomas disfóricos y sobre 
todo, el agotamiento emocional, destacan las alteraciones de conducta (conducta anormal del modelo asistencial o despersonalización de la relación con el cliente), se relaciona con síntomas físicos, como cansancio hasta el agotamiento, malestar general, junto con técnicas paliativas reductoras de la ansiedad residual, como son las conductas adictivas, que a su vez, median en deterioro de la calidad de vida, se trata de un síndrome clínico-laboral que se produce por una inadecuada adaptación al trabajo, aunque se dé en individuos considerados presuntamente "normales" y, por último, se manifiesta por un menor rendimiento laboral y por vivencias de baja realización personal, de insuficiencia e ineficacia laboral, desmotivación y retirada organizacional.

Se considera que los factores motivadores y de satisfacción personal están relacionados a factores de satisfacción laboral, sin embargo los factores estresantes pueden impactar en las percepciones del entorno, afectando las labores de los trabajadores. Esto se puede evidenciar en el estudio de Villamil, Sánchez, Paredes y Pineda (2012) sobre Influencia del clima organizacional sobre la satisfacción laboral en los empleados de la municipalidad de Choloma, en Honduras. Para la recolección de datos se trabajó con un cuestionario. Se tomó como base ocho dimensiones para la variable clima organizacional (autonomía, cohesión, confianza, presión, apoyo, reconocimiento, equidad e innovación) y para la variable satisfacción laboral seis dimensiones (satisfacción con el trabajo en general, con el ambiente físico, con la forma en que realiza su trabajo, con la oportunidad de desarrollo, con la relación jefe/subordinado, y con la relación remuneración). La muestra de 154 empleados encuestados determinó que existe un $64 \%$ de influencia del clima organizacional sobre la satisfacción de los empleados de la Municipalidad de Choloma.

El clima laboral es un factor importante en las empresas y las empresas son cada vez más competitivas, generando la necesidad de que las personas realicen su trabajo con la mayor calidad posible, con la capacidad de ejecutar una importante variedad de actividades, interesados en su capacitación permanente, y, si es necesario, dispuestos a prolongar sus jornadas laborales. Por ejemplo, Crespín (2012) en una investigación, realizada en Lima, Perú, expone la medición del nivel de percepción del clima organizacional que tienen los docentes de una institución educativa pública de la región Callao. Los resultados de esta investigación mostraron que el clima organizacional se encuentra en un nivel medio. 
Las percepciones, el sentir y la vivencia de los trabajadores es muy importante para poder conocer que es lo que pasa dentro de la empresa, para saber cómo mejorar y qué plan de acción realizar. Además, otro punto importante es ver como el clima laboral y el burnout afectan las labores diarias y el estado de ánimo de los trabajadores; en caso las percepciones sean negativas, es probable que el rendimiento y la productividad sea baja, causando poca rentabilidad a la empresa. Las empresas deben ser conscientes de que un buen clima laboral conlleva a tener más trabajadores felices, que van a trabajar con ganas de ser mejores, por otro lado, si estos trabajadores experimentan burnout, es probable que estén cansados, sin ganas de superarse ni crecer profesionalmente, por lo tanto, sin ganas de hacer las cosas de la mejor manera.

Después de todo lo expuesto, la presente investigación se plantea la siguiente interrogante: ¿Cuál es la percepción sobre el burnout y clima laboral de los trabajadores de una empresa privada de Lima Metropolitana?

\subsection{Justificación y relevancia}

En la actualidad, la investigación sobre el clima laboral y burnout es necesaria y esencial para cualquier empresa, porque ayuda a tener un indicador del grado de bienestar en los trabajadores, además de que con la información se puede realizar un plan de acción oportuno.

Estudiosos como Villa y Villar (1992), Goncalves (1997), Iriondo (2007), Hartog-Cuentas (2015) y Ocampo (2007) afirman que el clima laboral influye notoriamente en la eficiencia y la productividad de una empresa. Además, señalan que, si se conocen las percepciones sobre el clima laboral, la empresa se puede anticipar a los sucesos que se desencadenarían a partir del valor que tengan: si es bueno, se puede obtener muchos beneficios, tanto para la organización como para las personas que en ella trabajan. Caso contrario, se verán pérdidas económicas, conflictos, ausentismo, renuncias, etc.

El lugar de trabajo debe ser considerado como un factor prioritario para el bienestar del trabajador, ya que afecta directamente los aportes positivos a la productividad, la motivación laboral, el espíritu de trabajo, la satisfacción en el trabajo y la calidad de vida en general (Casas y Klijn, 2006). De esta forma se evidenciará cómo la buena salud ayuda a promover el desarrollo social económico y personal, 
entendiéndose este como el equilibrio ideal que puede tener un individuo. No obstante, las consecuencias que puede tener un lugar de trabajo no saludable pueden ser las opuestas a las anteriormente mencionadas a tal punto que afecten todos los factores del entorno de un individuo.

Por otro lado, la percepción de los colaboradores sobre el burnout y clima laboral, brinda información importante para mejorar los aspectos que ellos detecten negativos logrando aumentar el desempeño y rendimiento de los colaboradores, al igual que disminuyendo la rotación.

Para Goncalves (1999) el clima organizacional es "un componente multidimensional de elementos que pueden descomponerse en términos de estructuras organizacionales, tamaño de la organización, modos de comunicación, estilos de liderazgo de la dirección, entre otros." (Citado por Caligiore y Diaz, 2003, p. 645). Esta definición de clima ayuda a comprender lo importante que es estudiar este tema mediante la descripción de cada colaborador, ya que ellos son el motor de la organización y su percepción puede ayudar a mejorar aspectos que estén relacionados al rendimiento.

A pesar de que las asociaciones encontradas entre estos dos fenómenos provienen de estudios cuantitativos, es importante citarlos, ya que contribuyen en la comprensión del vínculo entre ambas, en el contexto empresarial.

Davila (2011) realizó en México, un estudio para establecer la relación entre el clima organizacional y el síndrome de burnout en una empresa mediana dedicada a la manufactura, donde se administró un Cuestionario de Clima Organizacional y el MBIGS (Maslach Burnout Inventory; General Survey). El cuestionario de Clima Organizacional considera cuatro dimensiones: naturaleza del trabajo, grupo de trabajo, estimulación moral y material, y condiciones del lugar de trabajo. El MBI-GS evalúa tres dimensiones (agotamiento emocional, cinismo y baja realización en su trabajo). Para analizar los datos utilizaron estadísticas descriptivas y el coeficiente de correlación de Spearman. En términos generales, los resultados de esta investigación muestran una tasa media y baja de presencia del burnout y asociaciones significativas de esta variable con el Clima Organizacional y con factores sociodemográficos.

Es en este sentido que la presente investigación permitirá brindar aportes interesantes e innovadores a la psicología, ya que el burnout y clima laboral no son 
temas que se hayan investigado anteriormente en el ámbito de Psicología organizacional desde una perspectiva cualitativa. Al tratarse de un estudio exploratorio, ayudará a descubrir nuevos conceptos y percepciones que ayuden a encontrar los posibles aspectos que producen burnout.

Por otro lado, en Perú, se pueden hallar investigaciones acerca el clima laboral, pero no hay muchas de burnout en entornos empresariales. Básicamente lo hallado se refiere a centros hospitalarios y educativos, por lo cual resulta de considerable importancia poder estudiarla en el ámbito organizacional, en la medida que la salud de los trabajadores es un punto importante, además, para la productividad y rentabilidad del negocio.

Así se han encontrado estudios que señalan que las empresas deben preocuparse por sus empleados, preocuparse porque estén satisfechos y motivados (Salazar, Leyton, Meza y Sáenz, 2012), ya que si es que no se atiende esos temas, es probable que exista alta rotación, ausentismo y bajo nivel de desempeño (Arbaiza, 2010).

El clima laboral es un indicador tan fuerte para las empresas, que ha llegado hasta la Amazonía peruana, como lo demuestra la Tesis de Pérez y Rivera titulada Clima organizacional y satisfacción laboral en los trabajadores del instituto de investigaciones de la Amazonía peruana (2013). Esto demuestra que no existen barreras para poder estudiar este fenómeno. Cada vez, se propaga más la importancia de estudiar el clima laboral y el burnout, para luego poder incluir un plan o guía que ayude a la empresa a llegar a sus objetivos estratégicos.

A pesar de que no hay muchos estudios cualitativos sobre estos factores, los estudios con esta metodología acerca del clima organizacional y de satisfacción laboral resultan imprescindibles, porque propician en los empleados la posibilidad de expresar su opinión sobre el funcionamiento de la organización y cómo se sienten en ella constituyendo así, la entrevista, un instrumento de indagación que funciona bajo la premisa de que se generan beneficios cuando se implementan acciones correctivas en los aspectos que lo requieran. También constituyen un excelente mecanismo para conocer de manera indirecta, cómo es la calidad de gestión de la organización (Pérez y Rivera, 2015). 


\subsection{Limitaciones}

Una limitación de este estudio es que las personas, por temor a hablar sobre temas de la empresa, no expresen con total sinceridad ni profundicen cuando se les plantean algunas temáticas. Esto, a pesar, de que tienen conocimiento de que la información que brinden es confidencial y será mantenida en estricta reserva.

Otra limitación, es la sobrecarga laboral que se produce día a día en los trabajadores, lo cual los lleva a querer concluir rápido la entrevista para continuar con sus tareas diarias, lo que a su vez disminuye la probabilidad de que brinden respuestas con mayor amplitud y desarrollo. 


\section{CAPÍTULO II: MARCO TEÓRICO}

Existen pocos estudios actuales relacionados al tema del burnout y clima laboral en trabajadores de empresas, ya que mayormente el burnout se relacionaba a personas que brindan servicios directamente a otras personas, como son los profesores, médicos, enfermeras, policías, entre otros.

\subsection{Las Percepciones}

Para Durkheim (1924), la percepción es "una propuesta teórica y metodológica que intenta develar los saberes del "sentido común" a partir de métodos e instrumentos diseñados para "atrapar" el material discursivo que constituye su fuente inagotable" (p. 32).

- Factores que influyen en la Percepción de personas.

Como indican Morales, Huici, Moya, Gaviria, López y Nouvilas (1999), algunos de los factores fundamentales son:

a) Características físicas y sociales

La percepción se ve influida por las características físicas y sociales del contexto donde se produce. Por lo tanto, la percepción social dependerá del contexto donde se ha producido.

b) Modo en que se produce el primer contacto

La valoración del primer contacto que inicia el proceso de percepción social, puede determinar toda la secuencia de acontecimientos posteriores.

c) Factores asociados al perceptor: Dentro de los cuales se puede destacar:

Las motivaciones y expectativas de los perceptores, que modelan los procesos cognitivos asociados a la percepción de personas (cómo se procesa y que tipo de información se busca). 
Familiaridad: La impresión que nos formamos es mucho más compleja y exacta cuanto más conocida es la persona.

Valor del estímulo: El valor que tiene la persona percibida para el perceptor, afecta la percepción. Tiende a darse una acentuación perceptiva de los estímulos favorablemente valorados.

Significado emotivo del estímulo: El valor emotivo depende del poder del estímulo para proporcionarnos consecuencias positivas o negativas.

Experiencia: Las personas que tienen más experiencia con cierto tipo de rasgos realizan, lógicamente, percepciones más acertadas.

d) Variables asociadas a la persona percibida

Este apartado hace referencia a los esfuerzos de la persona percibida por regular y controlar la información que presenta al perceptor. Especialmente la información referente a sí mismo. Estos esfuerzos (denominados manejo de la impresión) son un intento de influir sobre el proceso de formación de impresiones e influir sobre la conducta de los demás.

e) Factores relativos al propio contenido de la percepción.

Importancia del orden en el que se perciben los rasgos: para la formación de la primera impresión parece tener más importancia el efecto de primacía (mayor importancia de lo primero que se percibe); aunque en determinadas circunstancias puede predominar el efecto de recencia (mayor importancia de la información más reciente).

El tono evaluativo de los rasgos informativos: Cuando la información que se conoce contiene elementos positivos y negativos, estos últimos tienen mayor importancia en la impresión. Una impresión negativa es más difícil de cambiar que una positiva. Como posibles razones de este mayor interés por los aspectos negativos se ha sugerido una motivación egoísta pues una persona que posea rasgos negativos supone un mayor grado de amenaza. La información negativa tiene un mayor valor informativo porque la mayoría de las personas se esfuerza por suministrar una imagen positiva (Rothbart y Park, 1986). 
Por estos motivos, al realizar la investigación de corte cualitativo (en las entrevistas) es imprescindible tomar en cuenta los componentes de la percepción, así como los indicadores del burnout y el clima laboral. Esto servirá para tener mayor orden e información al momento de realizar las categorías, que nos llevarán a determinar los resultados.

\subsection{El Clima Laboral}

El clima laboral según Gellerman (1960) a quien se le atribuye la introducción del término en psicología organizacional, llegó a la conclusión de que clima era el "carácter" de una compañía e hizo una lista de pasos para analizarlo:

- Es necesario identificar a las personas en la organización cuyas actitudes son importantes.

- Estudiar a las personas y determinar cuáles son sus objetivos, tácticas y puntos ciegos.

- Revisar la historia de la compañía y prestar especial atención a las carreras de sus líderes.

- Es indispensable entregar toda la imagen con la idea de establecer denominadores comunes en lugar de agregar todas las partes para obtener una suma de ellos.

Forehand y Von Gilmer (1964), definen el clima laboral como un conjunto de características que describen a una organización y que las distinguen de otras organizaciones, estas características son relativamente perdurables a lo largo del tiempo e influyen en el comportamiento de las personas en la organización.

Es el ambiente que los empleados perciben de una serie de características propias de la empresa. De acuerdo al ambiente que hay dentro de la organización, es como se define si los comportamientos de los empleados son adecuados o no para el bienestar de la empresa. 
Un agradable clima organizacional se creará a partir del nivel de compromiso que tengan los agentes con su trabajo. Gilbert, Laschinger y Leiter mencionan el nivel de compromiso podría variar a partir de las condiciones en que se encuentre el trabajador, de esta forma señalan que la falta permanente de recursos organizacionales y financiación se ha traducido en la reducción de personal, reestructuraciones y complejidad en el trabajo, que básicamente define un ambiente caracterizado por estar saturado, que en resumen resulta en una baja calidad de vida en el trabajo, que finalmente puede traer como consecuencia el síndrome de burnout (2010). De igual forma Gilbert et al. (2010) plantean que el empoderamiento estructural puede ser una forma positiva para darle al trabajador la posibilidad de acceso a información, soporte, recursos y oportunidades para lograr un nivel satisfactorio de autorrealización, así mismo de transmitir información a los colegas para que estos vean que están en igualdad de condiciones y posibilidades de sobresalir.

Rodríguez, Retamal, Lizana, y Cornejo (2008), realizaron un estudio en Chile sobre el clima y satisfacción laboral como predictores del desempeño en una Organización Estatal Chilena. Esta investigación expuso que existe consenso respecto a que el clima organizacional y la satisfacción laboral son variables fundamentales dentro de la gestión de las organizaciones. Sin embargo, no está claro cuáles son los efectos específicos que tienen dichas variables sobre el desempeño laboral en general, ni tampoco sobre los aspectos específicos del desempeño, tales como el comportamiento normativo, la productividad y las relaciones sociales. El objetivo de este estudio fue determinar si el clima organizacional y la satisfacción laboral son predictores significativos tanto del desempeño laboral como de sus dimensiones específicas. La muestra fue un total de 96 trabajadores de un organismo público de la Región del Maule, a los cuales, se les aplicaron los cuestionarios de Clima Organizacional de Litwin y Stringer (1968) y de Satisfacción Laboral. Los cuestionarios fueron contestados de forma individual y en un solo momento. Esta aplicación fue realizada junto al proceso de evaluación anual de desempeño de la institución. En esta evaluación se aplicó un cuestionario confeccionado por la institución cuyo objetivo era evaluar tres dimensiones del desempeño de los funcionarios ("comportamiento funcionario, condiciones personales, rendimiento y productividad). El resultado fue que se pudo evidenciar que existe una relación significativa entre el clima, la satisfacción y el desempeño. Y que el desempeño se predice de mejor forma por las variables en 
conjunto. Considerando las dimensiones del desempeño, sólo el clima laboral es capaz de predecir significativamente el comportamiento funcionario y las condiciones personales, mientras que la satisfacción sólo predice el Rendimiento y la Productividad.

\subsection{El Burnout}

El Síndrome de Burnout, es considerado por la Organización Mundial de la Salud (OMS, 2000) como una enfermedad laboral que provoca detrimento en la salud física y mental de los individuos.

"Entre los riesgos psicosociales emergentes de la actividad laboral se encuentra el síndrome de quemarse por el trabajo (burnout), definido como una respuesta al estrés laboral crónico que se manifiesta en los profesionales de las organizaciones de servicio que trabajan en contacto con los clientes o usuarios de la organización, y cuyos síntomas más característicos son: pérdida de ilusión por el trabajo, agotamiento físico y emocional, actitudes negativas hacia los clientes de la organización, y, en determinados casos, sentimientos de culpa" (Gil Monte, 2005, p. 21).

El Síndrome de Burnout o Síndrome de Quemarse por el Trabajo es un tipo de estrés laboral crónico, que conlleva actitudes y sentimientos negativos hacia las personas con las que se trabaja, como respuesta ante hechos como sentirse emocionalmente agotado o por la falta de realización profesional (Maslach y Jackson, 1981).

En el mismo sentido, Shirom (1989), a través de una revisión de diversos estudios, concluye que el contenido del síndrome de burnout tiene que ver con una pérdida de las fuentes de energía del sujeto y lo define como "una combinación de fatiga física, cansancio emocional y cansancio cognitivo.

Cherniss (1982) postula que el burnout se da en un proceso de adaptación psicológica entre el sujeto estresado y un trabajo estresante, en el cual el principal precursor es la pérdida de compromiso. Describe el proceso en cuatro fases: fase de estrés, fase de agotamiento y fase de afrontamiento defensivo.

- Fase de estrés: Esta fase consiste en un desequilibrio entre las demandas del trabajo y los recursos de los que dispone el individuo para hacer frente a esos acontecimientos. 
- Fase de agotamiento: Se refiere a la respuesta emocional inmediata del sujeto ante dicho desequilibro, es decir que el trabajador presentará sentimientos de preocupación, tensión, ansiedad, fatiga y agotamiento.

- Fase de afrontamiento defensivo: Esta fase implica cambios en la conducta y en la actitud del trabajador, caracterizándose por un trato impersonal, frío y cínico hacia los clientes.

El modelo de Farber (1991) describe seis estadios sucesivos:

- Entusiasmo y dedicación.

- Respuesta de ira y frustración del trabajador ante los estresores laborales.

- No hay una correspondencia entre el esfuerzo y los resultados y recompensas.

- Se abandona el compromiso e implicación en el trabajo.

- Aumenta la vulnerabilidad del trabajador y aparecen síntomas físicos, cognitivos y emocionales.

- Agotamiento y descuido

El Modelo Procesual de Leiter surge a partir del modelo secuencial de Leiter y Maslach (1988) y plantea que la aparición del burnout se da a través de un proceso que empieza por un desequilibrio entre las demandas organizacionales y los recursos personales. Esto provocaría cansancio emocional en el trabajador, para luego experimentar la despersonalización como una estrategia de afrontamiento. El proceso concluye con baja realización personal como resultado de la ineficacia al afrontar los diferentes estresores laborales, es decir que las estrategias de afrontamiento no son afines con el compromiso exigible en el trabajo asistencial. 
Como se puede observar, son tres las dimensiones que explican la evolución del síndrome. De éstas, el agotamiento emocional es el aspecto clave en este modelo y se refiere a la fatiga, pérdida progresiva de energía, etc. La despersonalización experimentada por el trabajador se refiere a una forma de afrontamiento que protege al trabajador de la desilusión y agotamiento. Ésta implica actitudes y sentimientos cínicos, negativos sobre los propios clientes, que se manifiestan por irritabilidad y respuestas impersonales hacia las personas que prestan sus servicios. Y por último, la dificultad para la realización personal en el trabajo son respuestas negativas hacia sí mismo y el trabajo. Es el deterioro del autoconcepto acompañado de sensaciones de inadecuación, de insuficiencia y de desconfianza en sus habilidades.

A continuación, se presentarán algunos estudios de naturaleza cuantitativa, por la implicancia que tienen con el contenido del tema, ya que no se han encontrado estudios cualitativos que describan la vinculación del burnout y clima laboral.

Guzmán y Guzmán (2010), realizaron en Perú, un estudio para determinar los factores asociados al síndrome de burnout en el personal de Enfermería del Hospital Militar Central. Se obtuvo que la prevalencia del síndrome de burnout y factores asociados, del total de participantes que fueron 547, la mayoría presentaron estrés laboral asistencial. Esto determinó que existe una asociación con las siguientes variables: tiempo de servicio mayor de 12 años, estado civil, edad, situación laboral de contratado y baja motivación laboral, baja satisfacción laboral y alta insatisfacción laboral. Por otro lado hallaron que existía baja asociación estadística con el trabajo mayor a 40 horas semanales.

Hidalgo y Moreno (2010), realizaron en Colombia un estudio sobre la relación entre el clima organizacional y el síndrome de burnout en empleados de una firma de vigilancia en una empresa carbonera de la Guajira (Colombia). En este trabajo se planteó, como objetivo principal, describir la relación existente entre el clima organizacional (CO) y el síndrome de burnout (SB) en guardias de seguridad de una empresa colombiana productora de carbón. El tipo de investigación utilizado fue no experimental, de tipo transversal y la muestra estuvo conformada por 393 sujetos. De este grupo, solo dos individuos diligenciaron de manera incompleta los dos cuestionarios, por lo que la cifra válida se redujo a 391 personas. Como resultado se halló que no existe SB y el CO es bueno en la organización objeto del estudio. Estos resultados sugieren que un buen CO podría ser un factor protector para la aparición del 
SB en la organización, tal como lo sugieren otros estudios.

Núñez (2010), realizó un estudio en el Perú, que se titula: El síndrome de quemarse por el trabajo (SQT) en el profesorado de una zona andina del Perú: informe de investigación. El objetivo fue describir el síndrome de quemarse por el trabajo (SQT), factores asociados y consecuencias. Como resultados se obtuvo que menos profesores presentaban el síndrome de quemarse por el trabajo y la mayoría presentaron una o dos dimensiones con puntaje alto. El agotamiento emocional, la despersonalización y la baja realización personal están en grado medio. También se identificaron las consecuencias organizacionales del síndrome y las variables sociolaborales y sociodemográficas de riesgo y protección para el profesorado.

\subsection{Relación del Burnout y Clima Laboral}

Resulta importante describir la relación que pudiera existir entre el clima laboral y el burnout por lo que a continuación se describirán los aportes que al respecto han presentado diferentes autores.

Cuanto más centralizada sea la organización en la toma de decisiones, cuanto más compleja (muchos niveles jerárquicos), cuanto mayor es el nivel jerárquico de un trabajador, cuanto mayores sean los requerimientos de formalización de operaciones y procedimientos, mayor será la posibilidad de que se presente el síndrome de burnout (Apiquian, 2007).

Dávila y Romero (2010), realizaron una investigación en Venezuela, Caracas, cuyo título es "Relación entre el síndrome de burnout y la percepción sobre el clima organizacional en médicos del área de emergencia”. Esta investigación pretendió establecer la relación entre el síndrome de burnout y la percepción sobre el clima Organizacional. El estudio se llevó a cabo en clínicas y hospitales del área metropolitana de Caracas-Venezuela, en donde se les administró los instrumentos de medición a los médicos del área de emergencia. La variable de burnout se estudió mediante el Maslach Burnout Inventory Human Services Survey (MBI- HSS) y el clima organizacional a través del cuestionario de Clima Laboral de Litwin y Stringer. El estudio es de tipo correlacional, ya que el propósito fue medir el grado de relación entre ambas variables. Además el diseño de la investigación fue no experimental de campo debido a que no se manipularon las variables, sino que fueron observadas en su 
contexto natural. Como resultado se obtuvo que mientras menos favorable sea la percepción del clima, mayores son los niveles de padecer el síndrome de burnout. Cabe destacar que los médicos encuestados, obtuvieron un "Leve Nivel Medio del Burnout" y para la percepción del clima organizacional, obtuvieron que los médicos encuestados perciben a sus organizaciones de manera "Regular". También las variables ingreso mensual y beneficios, tanto a nivel interno como externo, están mal posicionados.

Otro factor del clima laboral que no se encuentra en la investigación anteriormente mencionada, es la motivación, la cual es fundamental para la elevación y creación de expectativa en el trabajador, ya que al profundizar o solidificar el clima organizacional dentro de todos los departamentos y áreas de la empresa, produce en los trabajadores competencias que se ven evidenciadas en sus comportamientos, como la responsabilidad, la autonomía a la hora de tomar decisiones relacionadas a su trabajo lo cual hace que la supervisión no sea tan estrecha sino más general; esto incentiva y da importancia, la recompensa dentro del clima organizacional también impide que haya aparición del síndrome de burnout, dado que por medio de esta herramienta o comportamiento de los niveles altos de las organización pueden cambiar la percepción de los miembros de la empresa por el trabajo realizado. (Galeano, Bromet y Galvis, 2012).

Campuzano y Álvarez (2012), realizaron un estudio en Perú, sobre el Síndrome de Burnout y su relación con el clima y la motivación laboral en los trabajadores de Sonigas S.A. de C.V Planta Tres Marías, el cual planteó como objetivo determinar la presencia del Síndrome de Burnout y en caso positivo el grado de desarrollo y la forma en que este se interrelaciona con las condiciones de salud, el clima, la motivación, el desempeño y la satisfacción laboral en la empresa SONIGAS en Tres Marías. Grupo SONIGAS planta Tres Marías, está conformado por 50 trabajadores de los cuales el $54.8 \%$ pertenecen a las áreas operativas, un $38.7 \%$ al área administrativa y un $6.4 \%$ desarrollan actividades mixtas; de estos se seleccionaron a 31 trabajadores, constituyéndose en un $62 \%$ de la población total obteniéndose una representatividad de todas las aéreas. Se utilizó el cuestionario del Maslach Burnout Inventory, Job Descriptive Index, test psicológico de motivación, un cuestionario de clima laboral, una evaluación del desempeño y un cuestionario de datos generales y de salud. Fue un estudio de tipo descriptivo, transversal y analítico, en el cual se describieron las variables en forma bivariada, teniendo en cuentas tres variables dependientes (síndrome 
de burnout, desempeño laboral y clima laboral), en relación a los posibles factores relacionados. Como resultados se obtuvo que cuando las personas presentan bajos niveles de motivación, satisfacción clima y desempeño laboral, estas se encuentran en riesgo de padecer burnout. 


\section{CAPÍTULO III: OBJETIVOS}

\subsection{Objetivos}

- Describir las percepciones de los trabajadores sobre los indicadores del síndrome de burnout y clima laboral en una empresa privada de Lima Metropolitana.

- Identificar cómo están vinculadas las percepciones sobre el clima laboral y burnout de los trabajadores de una empresa privada de Lima Metropolitana.

- Describir las características de la vinculación existente en las percepciones tanto del clima laboral como del burnout de los trabajadores de una empresa privada de Lima Metropolitana. 


\section{CAPÍTULO IV: MÉTODO}

\subsection{Tipo y diseño de investigación}

El presente estudio se enmarca en una perspectiva de investigación cualitativa, pues lo que se busca es reflejar las percepciones de los trabajadores de una empresa privada sobre el clima laboral y burnout. Esta perspectiva ha permitido encontrar hallazgos significativos, los cuales fueron descritos, registrados, interpretados $\mathrm{y}$ analizados sistemáticamente. Se enfatiza que el procedimiento metodológico en la recolección de los datos fue la entrevista.

En este contexto, es de tipo exploratorio, ya que buscó examinar un tema o problema de investigación poco estudiado en las empresas y que además no ha sido abordado en su conjunto (clima laboral y el burnout). Fidias (2012) afirma que: "la investigación exploratoria es aquella que se efectúa sobre un tema u objeto desconocido o poco estudiado, por lo que sus resultados constituyen una visión aproximada de dicho objeto, es decir, un nivel superficial de conocimientos" (p.23). Este tipo de estudio ayudó a aumentar el grado de familiaridad con estos fenómenos relativamente desconocidos, obtener información sobre la posibilidad de llevar a cabo una investigación más completa sobre el burnout y clima laboral en la vida real, identificar conceptos sobre estos y establecer prioridades para investigaciones posteriores. Además, el burnout y el clima laboral no son muy estudiados en conjunto, por eso también podría ser importante realizarlo y poder obtener las descripciones que ayuden a futuras investigaciones.

Además es de tipo descriptivo, ya que el estudio tiene como objetivo especificar, características, propiedades, rasgos de los fenómenos analizados. "Los estudios descriptivos buscan especificar las propiedades importantes de personas, grupos, comunidades o cualquier otro fenómeno que sea sometido a análisis." (Hernández, 1991, p.60).

Se utilizó un diseño narrativo a fin de identificar y clasificar estas percepciones, así como para recoger la información relevante que permitió su categorización, análisis e interpretación acerca de las justificaciones, razones y otras cogniciones con las que los trabajadores describen el clima laboral y burnout de la empresa donde trabajan. 
En los diseños narrativos el investigador recolecta datos sobre las historias de vida y experiencias de determinadas personas para describirlas y analizarlas. Son de interés las personas en sí mismas y su entorno. Creswell (2005) señala que el diseño narrativo en diversas ocasiones es un esquema de investigación, pero también es una forma de intervención, ya que el contar una historia ayuda a procesar cuestiones que no estaban claras. Se usa frecuentemente cuando el objetivo es evaluar una sucesión de acontecimientos.

Heidegger (2006) por otra parte, precisa que la fenomenología se enfatiza en la ciencia de los fenómenos; ésta consiste en "permitir ver lo que se muestra, tal como se muestra a sí mismo y en cuanto se muestra por sí mismo"; por consecuencia, es un fenómeno objetivo, por lo tanto, verdadero y a su vez científico.

Resumiendo, conforme a los aportes tanto de Husserl como de Heidegger, se define a la fenomenología como el estudio de los fenómenos (o experiencias) tal como se presentan y la manera en que las viven las propias personas.

Tomando en cuenta la literatura revisada, el estudio también se planea desde la perspectiva fenomenológica porque parte de las experiencias vividas de los participantes. Su objetivo es prioritariamente el campo de los fenómenos tal como son vividos y experimentados por los colaboradores de la empresa. Se buscó conocer los significados que los trabajadores, a través de su experiencia, brindan sobre el clima laboral y burnout, al igual que lo importante que es aprender el proceso de interpretación por el que ellos describen su entorno de clima laboral, burnout y su forma de actuar en consecuencia. Además, el trabajo se sustenta en que existe relativamente poca investigación sobre estos constructos desde la perspectiva cualitativa.

\subsection{Participantes}

En las investigaciones cuantitativas, lo que hace el investigador (en comunicación social) es escoger una población, seleccionar la muestra, proceder al muestreo probabilístico, siempre cuidando de que sea representativa a toda la población. En la investigación cualitativa, "la lógica de la muestra se basa en estudiar a profundidad algo a fin de que sea válido. Usualmente esto se hace en pocos casos seleccionados en forma intencionada" (Pineda, De Alvarado y De Canales, 1994, p.120). 
"Frente al muestreo probabilístico la investigación cualitativa propone estrategias de selección de informantes que suponen una selección deliberada e intencional. Las personas o grupos no se seleccionan a la azar para completar una muestra de tamaño $n$, se eligen uno a uno de acuerdo con el grado en que se ajustan a los criterios o atributos establecidos por el investigador, incluso en algunos estudios se elige a una sola persona o institución como caso y, desde luego, nunca a partir de una tabla de números aleatorios" (Rodríguez, Gil y García, 1996, p. 19).

Por lo tanto, la selección de los participantes del estudio se realizó de forma intencional ya que se buscó que todos los participantes fueran del área de Administración y Finanzas y que tengan un nivel de responsabilidades, al igual que carga laboral, elevada. El gerente del área identificó a los participantes, ya que indicó quienes tienen mayor nivel de responsabilidad y carga laboral. Estas personas fueron elegidas para realizarles la entrevista semi estructurada y fueron de diferente sub áreas como: Control de Gestión, Cobranzas, Contabilidad, Servicios Generales, Tesorería y Finanzas.

El número de participantes se conformó teniendo en cuenta el punto de saturación de la información obtenida (es decir cuando los participantes entrevistados dejen de aportar nuevos elementos y la información recolectada sea reiterativa).

¿Hasta dónde continuar recabando información, entonces? Dice Morse (1995) el precepto exige recolectar datos hasta que ocurra la saturación. Pero ¿qué significa saturación? ¿Cuáles son sus fundamentos y sus principios? Para Krueger (2000), en el ámbito de la investigación cualitativa se entiende por saturación el punto en el cual se ha escuchado ya una cierta diversidad de ideas y con cada entrevista u observación adicional no aparecen ya otros elementos. Mientras sigan apareciendo nuevos datos o nuevas ideas, la búsqueda no debe detenerse.

En los estudios cualitativos casi siempre se emplean muestras pequeñas no aleatorias, lo cual no significa que los investigadores naturalistas no se interesen por la calidad de sus muestras, sino que aplican criterios distintos para seleccionar a los participantes (Salamanca y Martín-Crespo, 2007).

La muestra se tomó de una población de 35 colaboradores del área de Administración y Finanzas de una Empresa privada del rubro químico de Lima Metropolitana. El estudio finalmente se realizó con diez trabajadores entre hombres y 
mujeres, que tenían como mínimo tres meses laborando dentro de la empresa, cuyas edades oscilan entre 20 y 55 años y que al momento de la entrevista se encontraran laborando en dicha empresa. Los participantes fueron entrevistados en el horario de trabajo, en una sala de reuniones de la empresa, para que así no tengan problemas con el traslado. Por otro lado, la entrevista se realizó de forma anónima, para que los participantes puedan expresarse libremente, sin ninguna restricción.

Para tener un mejor detalle de los aspectos demográficos de la muestra, se realizó el siguiente cuadro con el total de los colaboradores entrevistados (10 personas).

Tabla 1

Datos demográficos de los colaboradores entrevistados

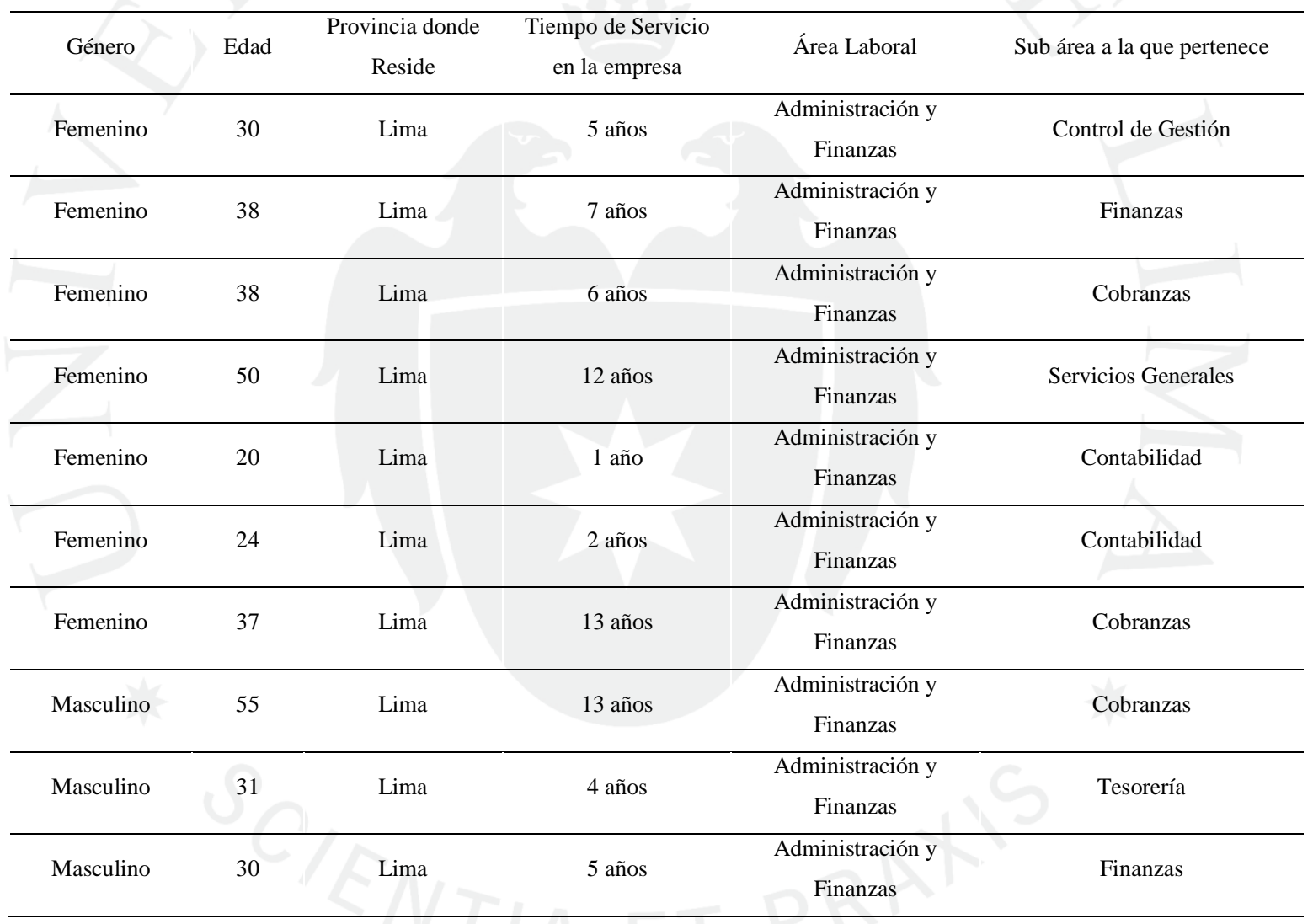

\subsection{Técnicas de recolección de datos}

La entrevista, en la investigación cualitativa, es un instrumento técnico que tiene gran sintonía epistemológica con este enfoque y también con su teoría metodológica.

Kvale (1996) señala que el propósito de la entrevista de investigación cualitativa es obtener descripciones del mundo vivido por las personas entrevistadas, con el fin de lograr interpretaciones fidedignas del significado que tienen los fenómenos descritos. 
Para ello nos ofrece una guía con diferentes rasgos que caracterizan la entrevista. Igualmente, el mismo autor nos ofrece otros criterios que señalan la preparación o calificación que debe tener o adquirir un buen entrevistador.

Así entendida, la técnica de la entrevista es, en gran medida, un arte; sin embargo, lógicamente, las actitudes que intervienen en ese arte son, hasta cierto punto, susceptibles de ser enseñadas y aprendidas; como ocurre en muchos otros campos de la actividad humana, sólo se requiere disposición e interés en aprender (Martínez, 2006).

La entrevista semi estructurada, permite que el investigador tenga un guion, que ayude a recoger los temas que debe tratar a lo largo de la entrevista. Sin embargo, el orden en el que se abordan los diversos temas y el modo de formular las preguntas se dejan a la libre decisión y valoración del entrevistador.

La virtud genuina de las entrevistas cualitativas es su apertura. No existen procedimientos o normas estandarizadas para realizar una entrevista de investigación o toda una investigación con entrevistas (Kvale, 2008). Por esto para realizar entrevistas para una investigación cualitativa se requiere también una cuidadosa y bien pensada planeación.

Kvale (1996), establece siete pasos fundamentales para estas entrevistas.

- Selección de tema. Se refiere a la clarificación conceptual y al análisis teórico del tema que se investigará. Es importante formular el propósito y las preguntas de investigación antes de iniciar cualquier entrevista. Resulta fundamental tener claro el motivo de una investigación antes de definir el método a utilizar.

- Diseño. Como primordial aparece el diseño del estudio, tomando en consideración los siete estadios antes de iniciar las entrevistas. El diseño del estudio se realiza con base en el conocimiento que se busca y teniendo en cuenta las implicaciones éticas del mismo.

- Entrevista. Para su realización es necesaria una guía, así como una actitud reflexiva del conocimiento que se pretende. La relación interpersonal que surge en la situación de la entrevista debe tenerse siempre presente. 
- Transcripción. La preparación, con propósitos de análisis, del material obtenido en la entrevista usualmente implica convertirlo en material escrito.

- Análisis. Se requiere decidir, sobre la base de las preguntas y de los objetivos de estudio, cuál marco referencial interpretativo será el más adecuado.

- Verificación. En este punto se valoran la confiabilidad y la validez. y ésta, a la que el estudio basado en entrevistas corresponde al propósito de lo que se busca investigar.

- Preparación del informe. Se refiere a preparar la comunicación final del estudio, en forma consistente con los criterios científicos e incluyendo los factores éticos de la investigación. Requiere una redacción que facilite su lectura.

Así como los instrumentos utilizados en investigación cuantitativa son sujetos a controles estadísticos para asegurar su confiabilidad, en investigación cualitativa, el instrumento humano - el investigador - puede asegurar su confiabilidad mediante entrenamiento y técnicas de análisis.

Selltiz (1981) menciona en su libro Métodos de Investigación en las Relaciones Sociales, que el cuestionario al igual que en la entrevista basa su fiabilidad sobre la validez de los informes verbales; en el cuestionario la información que se obtiene se limita a las respuestas escritas de los sujetos ante preguntas ya preparadas, sin embargo en la entrevista como están presentes entrevistado y entrevistador existe una mayor oportunidad en la formulación de preguntas y respuestas.

Existen diversas formas como la investigación cualitativa asegura la validez y la confiabilidad de los hallazgos; algunas de ellas se relacionan con el investigador, otras con la recolección de datos y otras más con el análisis de la información (Patton,1990).

Para determinar las áreas que contempla la entrevista, se tuvo como guía un cuestionario de clima laboral, el cual se creó en una clase de Clima Laboral y Cultura, que posteriormente fue validada por el método de jueces (cinco jueces). Además, se 
incluyeron preguntas sobre burnout tomando en cuenta los indicadores de burnout según la autora Christina Maslach, que son: Agotamiento Emocional, Despersonalización y la falta de realización personal.

Posteriormente, para validar la entrevista semi estructurada (método cualitativo) se utilizó la modalidad de jueces (4 Jueces), concluyendo con un nivel de concordancia interpretativa por consenso entre todos. Gracias a este método, se incluyeron puntos de vistas adicionales externos que contribuían a la visión de debilidades que el investigador no podía detectar.

El juicio de expertos es un método de validación útil para verificar la fiabilidad de una investigación que se define como "una opinión informada de personas con trayectoria en el tema, que son reconocidas por otros como expertos cualificados en éste, y que pueden dar información, evidencia, juicios y valoraciones" (Escobar-Pérez y Cuervo-Martínez, 2008, p. 29).

La entrevista está compuesta por 24 preguntas relacionadas a cada indicador, la cual sirvió para identificar y describir las características del clima laboral y burnout según las percepciones de los trabajadores de una empresa privada. El cometido del entrevistador consistió en motivar a los participantes a expresarse con libertad acerca de todos los temas del guion y en registrar las respuestas, normalmente mediante una grabadora.

Las preguntas se diseñaron de tal manera que la información obtenida fuera clara y sin ambigüedades. Las preguntas se formularon con bastante cautela y se brindó pausas al momento de hablar, para que sea una conversación más que un interrogatorio: Se tomó el cuidado necesario en la presentación de las preguntas ya que el tema de por sí es sensible en la medida que las personas podrían experimentar temor o preocupación al sincerarse pensando que la información podría traer consecuencias negativas en su centro laboral.

\subsection{Procedimiento de recolección de datos}

Se coordinó con las autoridades de la empresa privada para poder realizar entrevistas semi estructuradas a las personas del área de Administración y Finanzas (esto significa que se solicitó autorización para convocar durante aproximadamente 30 minutos a los colaboradores durante su horario de trabajo). Después de la reunión con 
las autoridades se pudo lograr el permiso respectivo. Se hizo especial énfasis en la importancia del estudio para analizar las percepciones del clima laboral y burnout que tienen los trabajadores de la empresa, explicándoles que puede servir para crear recomendaciones que permitan mejorar el clima laboral y la salud de los mismos. Por otro lado, se les explicó que las entrevistas son totalmente confidenciales al igual que el nombre de la organización.

Posteriormente, se conversó con el Gerente de Administración y Finanzas para elegir a los participantes que tuvieran mayores responsabilidades y carga laboral. Una vez identificados, se coordinó y planificó con los trabajadores las diferentes fechas y horarios según la disponibilidad de cada uno. Las entrevistas se realizaron dentro de las instalaciones de la empresa (sala de reuniones). La sala de reuniones, fue un lugar idóneo para esta labor ya que era un espacio tranquilo y libre de interrupciones.

Cuando el participante llegó a la cita, se le explicó la naturaleza del estudio y los términos para la confidencialidad, además se le entregó la ficha de consentimiento informado, donde la entrevistadora explicó cada punto del consentimiento informado, además de contestar cualquier duda que pudieron presentar. Cuando finalizaron con el proceso de completamiento de datos, se realizó un breve resumen oral de la investigación, para que no existiera ninguna incertidumbre durante la entrevista. Se formuló cada pregunta de la entrevista semi estructurada y se realizaron preguntas adicionales si es que se necesitaba mayor especificación. Una vez realizada la entrevista, se le agradeció al colaborador por la participación y que ante cualquier duda sobre la investigación puede contactarse con la entrevistadora para que pueda resolverla.

Este procedimiento se realizó con los diez participantes, ya que la saturación de información (percepciones), proporcionó el final de las entrevistas y la cantidad de entrevistados.

\subsection{Estrategias de análisis de datos}

Para cumplir con los objetivos de esta investigación y de acuerdo a la forma como fue diseñado el instrumento de investigación, el análisis de datos se realizó con un enfoque cualitativo. 
De acuerdo con Hernández, Fernández y Baptista (2014), uno de los retos para realizar un análisis de tipo cualitativo es saber ordenar y clasificar el gran volumen de información que se llega a recolectar para posteriormente discriminar aquella que no es tan relevante para el objeto de estudio.

Se registró sistemáticamente la información recolectada, ya que cada encuentro fue minuciosamente desgrabado y transcrito para poder visualizar las respuestas, de modo de tener claridad acerca del camino a seguir en el siguiente, además se pudieron realizar técnicas de observación para saber si el entrevistado se sentía cómodo y si brindaba respuestas sinceras.

Se realizó la codificación de las entrevistas, la cual consistió en realizar una transformación de los “datos brutos" a los “datos útiles”. Las operaciones implicadas en esta etapa son la fragmentación del texto, es decir, el establecimiento de unidades de registro, y la catalogación de elementos (Reaño y Campos, 2012). Esta es la etapa más larga, aquí es donde el entrevistador realizó una lectura detallada de cada entrevista para ir seleccionando la información útil que sirvió para el estudio, agrupando y reagrupando los datos significativos, uniéndolos por colores y en unidades definidas por similitud.

Luego, se asignó a cada unidad temática una categoría y se asignaron subcategorías (propiedades descriptivas) para lograr mayor especificación.

"Las categorías se construyen desde la teoría como punto de referencia y desde la experiencia o la realidad empírica" (Galeano, 2004, p. 41).

Con esta información, se pudieron presentar los resultados y conclusiones, que luego permitieron derivar las recomendaciones más oportunas. 


\section{CAPÍTULO V: RESULTADOS Y DISCUSIÓN}

Se describirán los resultados tomando en cuenta el orden de los objetivos planteados. El primero de los objetivos del presente estudio es describir las percepciones de los trabajadores sobre los indicadores del síndrome de burnout y clima laboral.

Para describir las percepciones se obtuvieron diez categorías en total, siete de clima laboral: Estructura, Satisfacción con la empresa y el puesto, comunicación, Liderazgo, carga de trabajo, Trabajo en Equipo, Desarrollo Personal y tres de burnout: Agotamiento Emocional, Despersonalización y Realización Personal.

\section{a) Categoría: Estructura}

En primer lugar, los colaboradores perciben que los objetivos y responsabilidades no se encuentran establecidos en documentos formales y no están al alcance de todos, además, las funciones que realizan actualmente pueden estar en el plan de trabajo que tiene cada uno, pero no necesariamente son las funciones que se realizan en el día a día, pueden haber muchas más funciones que no se encuentran registradas. Todo esto, puede causar alta carga laboral y que algunas áreas estén sobrecargadas, como lo perciben los trabajadores actualmente.

Entrevistado 1: "...No, osea si existen objetivos, ya pero que estén ehh...como que puestos en papel, no no están..."

Entrevistado 3: "...la parte de objetivos, osea si está dentro del plan de cada uno, pero de hecho hay muchos más objetivos que hacemos..."

Entrevistado 3: "...Y en mi caso debería ver el análisis completo del flujo no solo ver finanzas como algo separado, entonces finanzas tiene más carga laboral que otros..."

Entrevistado 4: "...Todo eso está en el perfil del puesto, claro que no todos tienen ese formato..."

Entrevistado 5: "...Sí están definidas las responsabilidades y los objetivos, siempre formalmente en papeles o documentos virtuales..." 
Entrevistado 6: "...se ha elaborado un manual de funciones de mi área, aún no está cien por ciento definido, faltaría pasarlo a actos formales..."

Entrevistado 7: "...creo que todos sabemos cuáles son nuestros labores, aunque a mí nunca me han dado ningún papel formal...."

Entrevistado 8: "... a los usuarios nos permite tener presente los objetivos para poder cumplirlos en el día a día..."

Entrevistado 9: "...no conozco que existan documentos formales como manuales o perfil de puesto que sea dado a conocer en el momento que cada uno asume sus funciones en la empresas..."

Entrevistado 10: "...el tema de personal que me apoye es un poco escaso porque el ingreso de facturas diario es demasiado..."

\section{b) Categoría: Satisfacción con la empresa y el puesto}

En cuanto a la segunda categoría, se encontró que los trabajadores disfrutan de lo que hacen, ya que el ambiente laboral y la cultura de la empresa son factores que influyen bastante en la percepción positiva que tienen del puesto de trabajo y la empresa. Además, perciben que las funciones de su puesto van acorde a sus gustos y aptitudes y se sienten motivados por los retos y resultados que pueden realizar en el día a día, aunque algunos piensan que si tuvieran un incentivo económico o un ascenso, tendrían mayor motivación en su puesto de trabajo. Por otro lado, creen que el reconocimiento que les brindan es lo que les motiva e impulsa a realizar bien tu trabajo.

Entrevistado 1: "...creo que considero bastante el clima, o sea el ambiente de trabajo es muy bueno, siempre lo he dicho, este de echo que también uno de los factores es que con los que me rodeo, con el entorno con el que trabajo cotidianamente..."

Entrevistado 2: "...me gusta bastante, estoy satisfecha..."

Entrevistado 3: "...o sea tu puedes hacer un montón de cosas, pero si no te lo reconocen, por más que tú te motives, no se puede..."

Entrevistado 3: "...sí, claro que sí, me encanta la empresa..." 
Entrevistado 4: "...sí, porque son retos y muchas cosas nuevas que aprender, me gustan los retos y este siento que teniendo retos puedo desarrollarme mejor profesionalmente..."

Entrevistado 4: "...me gusta en lo que me desempeño..."

Entrevistado 5: "...Sí, considero que asumo gran responsabilidad, preparando información para la toma de decisiones estratégicas en la Compañía..."

Entrevistado 6: "...siempre me he sentido a gusto con la gente y con los ideales de la empresa y me he adaptado bien a los cambios..."

Entrevistado 7: "...siento que faltan más incentivos motivacionales, cómo por ejemplo, un incentivo económico...."

Entrevistado 8: "...A veces, cuando los objetivos van por el lado de análisis; si me motiva o cuando se hace las cosas bien y lo reconocen..."

Entrevistado 9: “...Disfruto de las funciones que realizo en el sentido de que tengo un clima de trabajo bastante agradable..."

Entrevistado 10: "...el ambiente laboral es muy grato y se preocupan por el bienestar de los trabajadores cosa que en la mayoría de empresas no se encuentra..."

\section{c) Categoría: Comunicación}

En esta categoría se encontraron diferentes percepciones sobre la comunicación dentro de la empresa. Los colaboradores perciben la comunicación de manera horizontal, pero en temas más formales, sienten que la comunicación se realiza de manera vertical. Además, perciben que existe una buena comunicación dentro de la empresa, lo que ayuda que las personas les escuchen y siempre estén dispuestos a escuchar cuando tienen algo que decir, ya sea una idea o recomendación. En cuanto a la comunicación con los jefes, todos concuerdan que su comunicación con ellos es bastante fluida y que siempre están dispuestos a escuchar sus comentarios e ideas. Por otro lado, perciben que se ha reforzado un poco la comunicación sobre la información de la empresa, como los valores, la misión, la visión, los objetivos, etc, pero que todavía falta interiorizar y distribuir mejor la información, para que llegue a todos los 
colaboradores. Para algunos colaboradores, no siempre los escuchan cuando dan una idea o propuesta, además un entrevistado cree que existen preferencias.

Entrevistado 1: "...yo creo que si es como que horizontal ya?..."

Entrevistado 1: "...es medio renegón pero si sabe escuchar, además siempre pide nuevas ideas..."

Entrevistado 2: "...bastante comunicación se maneja de manera horizontal, pero hay bastante comunicación que se maneja a nivel gerencial..."

Entrevistado 3: "...si, si hay un esfuerzo para hacer eso, creo que a la mayoría de gente le llega toda la información..."

Entrevistado 4: "...es horizontal, yo veo que todo el mundo siempre están abiertos a escucharte, desde el más alto hasta el más bajo..."

Entrevistado 4: "...si, ahora si se comunican bastante, son bien entendibles, se hacen muchas campañas para interiorizar..."

Entrevistado 5: "...Es bastante fluida. Escucha constantemente y mantiene disposición positiva para tomar nuevas ideas y alternativas..."

Entrevistado 6: "...Creo que por lo general es horizontal, porque te dan la libertad de comunicarte directamente con tus superiores inmediatos con libertad...."

Entrevistado 6: "...Sí, cuando se plantea una idea para mejorar nuestros procesos, esta es escuchada y evaluada para ponerla en práctica...."

Entrevistado 7: "...mis comentarios no influyen en una toma de decisión, a pesar de estar involucrada en el tema..."

Entrevistado 8: "...No, pues a veces entre cargos supongo que saben mas y escuchan menos..."

Entrevistado 9: "...Considero que comunican adecuadamente los planes y objetivos, sin embargo, creo que la misión y visión no son conocidas por todo el personal de la empresa y en realidad debería darse la importancia que tienen en la medida en que las actividades del día a día contribuyan en la misión y visión..."

Entrevistado 10: "...tengo un poco de recelo ya que siento que tiene preferencia con una persona del equipo y siempre conversa con ella, se publican fotos, frases, y eso me incomoda, por eso trato de mantenerme al margen ..." 
Entrevistado 10: "...Horizontal, ya que todos los que trabajamos ahí tenemos un trato de "tú a tú", es decir todos podemos hablar de manera libre con los jefes, gerentes de nuestras labores y de las cosas que nos inquietan...."

\section{d) Categoría: Liderazgo}

En cuanto a las percepciones que tienen los colaboradores con el liderazgo que existe dentro de la empresa, se percibió que los líderes están capacitados en temas generales, pero que todavía necesitarían realizar más capacitaciones para que puedan desarrollar tareas o responsabilidades como líderes. Por otro lado, perciben que en la empresa no se fomenta el liderazgo, ya que no existen capacitaciones para mandos medios o una línea de carrera establecida para cada área. La mayoría concuerda que el estilo de liderazgo que existe es participativo, es de un líder que comparte la información que obtiene, que está comprometido con la empresa, con sus colaboradores y que siempre está pendiente de los demás. Los colaboradores perciben de manera positiva a los líderes, ya que los valoran y confían en ellos.

Entrevistado 1: "...es fácil identificar las cabezas, pero creo que no ha habido un tema de potencialización de cada uno no?, por el hecho de que no se han visto capacitaciones, este... no hay programas de desarrollo de personas, muchas personas no tienen línea de carrera..."

Entrevistado 2: "... yo creo que los que son líderes participan, o sea si no no serían líderes pues no ?...bajan los objetivos, que se comunican con las personas que deben comunicarse..."

Entrevistado 3: "...bueno básicamente, acá el líder de la empresa, tiene que ser una persona, uno que muera por la empresa..."

Entrevistado 4: "...son líderes participativos, este... como que comprometidos, comparten con los demás, son líderes cercanos..."

Entrevistado 5: "...yo creo que algunos sí, pero que todavía les falta entender y capacitarse en algunos aspectos para que puedan llegar a ser líderes verdaderos..."

Entrevistado 5: "...Varía de acuerdo a las áreas. En algunos casos sí tienen la experiencia, otros han ascendido en la compañía por su desempeño, pero no 
necesariamente por tener una buena gestión como líderes. Pero puedo decir que es un estilo participativo y que siempre escuchan a las personas..."

Entrevistado 6: "...nuestro líder ha comprendido que debe ser compañero y ser esto no solo mejora nuestra rendimiento sino muestra una mejor imagen ante otros grupos de trabajo..."

Entrevistado 7: “...No todos, hay líderes que les falta ser capacitados, no saben enseñar ni escuchar..."

Entrevistado 8: "...Existen hechos que no me llevaría a calificar que son buenos lideres..."

Entrevistado 9: "...existe una relación cercana con los niveles jerárquicos inmediatos...."

Entrevistado 9: "...Siento que hay líderes en los niveles más superiores de la empresa que no están bien capacidades en comunicación efectiva y empatía..."

Entrevistado 10: "...Algunas veces, ya que si hacen una buena chamba con el tema de la comunicación y motivación, pero algunas veces se desvían y se enfocan a hacer vida amical con algunas personas del área, siendo así el ambiente un poco incómodo, porque no deberían existir preferencias...."

Entrevistado 10: "...El estilo de liderazgo que tienen nuestros jefes es que tratan de mantenernos unidos como equipos, fomentando la comunicación..."

\section{e) Categoría: Carga de Trabajo}

Los colaboradores perciben que la carga laboral no está equitativamente distribuida por áreas, expresan que hay áreas que tienen mucho más trabajo que otras. Además, la mayoría no termina sus funciones en el horario de trabajo, por lo tanto, deben quedarse más horas o llegar antes para poder avanzar con sus tareas. Por otro lado, perciben que el trabajo no perjudica su tiempo personal, ya que son capaces de organizarse para poder realizar sus tareas y las cosas que tienen agendadas que no sean laborales. Aunque algunos si se sienten agobiados y dejan de lado a su familia o vida personal. Piensan que la empresa es flexible en cuanto a permisos o temas personales que los colaboradores puedan tener. Uno de los participantes cree que si no llega a realizar 
algún compromiso personal a causa de la cantidad de trabajo, eso se puede compensar después.

Entrevistado 1: "...hay algunas áreas más pesadas que otras, por ejemplo, contabilidad, este... no la puedo comparar con tesorería porque tienen mucha más carga operativa, pero creo que de acuerdo a los recursos que se les dan si estaría bien dividido..."

Entrevistado 2: "...podría ser que algunas son más cargadas..."

Entrevistado 2: "...por eso vengo ahora más temprano, para avanzar más cosas y no quitarle tiempo a mi hijo en la noche..."

Entrevistado 3: "...En la medida en que yo me ordene puedo saber que van a haber días en los que me tengo que quedar y ya de una u otra forma tratare de compensarlo con mi familia..."

Entrevistado 4: "...Me quedo uff siempre, vengo fines de semana, siempre me quedo como dos o 3 horas más fuera del horario establecido..."

Entrevistado 5: "...la empresa tiene una cultura en la que probablemente todos viven mucho el día a día y tienen bastante carga laboral, entonces no sé si podría decir que el trabajo está repartido equitativamente..."

Entrevistado 5: "...yo creo que definitivamente puedes encontrar un balance, así como hay momentos que tienes un tema personal en el horario de trabajo y me ha pasado que han sido súper flexibles conmigo..."

Entrevistado 6: "...no, tengo que llegar más temprano o retirarme un poco más tarde y a veces aun así no termino algunos pendientes...."

Entrevistado 7: "...nunca me alcanza, siempre me quedo más horas, a veces ni almuerzo...."

Entrevistado 7: "...Sí, sobre todo es carga de trabajo operativo, no veo mucho a mis hijos porque llego tarde a mi casa..."

Entrevistado 8: "...en los cierre de mes no, siempre me quedo más en esas fechas...." 
Entrevistado 9: "...La diferencia entre la carga de trabajo se siente si se considera el número de personas que hay en cada área para determinadas funciones repartidas..."

Entrevistado 9: "...debería cumplir mis horas, pero siempre hago muchas más de las que debería hacer..."

Entrevistado 10: "...Algunas veces, desde mi punto de vista, siento que me sobrecargan demasiado el trabajo, en lo personal, siento que deberían ser un poco más conscientes de lo que una persona puede dar, ya que si se tienen demasiada carga laboral es difícil poder hacer bien las cosas al $100 \%$ porque tienes presión..."

\section{f) Categoría: Trabajo en Equipo}

Los participantes perciben que existe trabajo en equipo dentro de la empresa, sienten que pueden contar con su equipo, se sienten apoyados por ellos incondicionalmente. Por otro lado, piensan que existe en el área compañerismo y confianza necesaria en el trabajo, pero que en otras áreas no cuentan con ninguna de las dos. Algunos participantes no perciben tanto compañerismo, ni el apoyo necesario por todo su equipo, ya que es un equipo nuevo y todavía se están conociendo.

Entrevistado 1: "...espero que sí, antes yo sentía que sí, pero ahora que es un equipo nuevo, no te podría dar una opinión muy acertada porque todavía no sé cómo va a ser..."

Entrevistado 1: "...creo que es más por áreas no, o sea yo te puedo decir que la gerencia de administración y finanzas hay bastante confianza en el equipo, pero si trasciendes la gerencia hay desconfianza..."

Entrevistado 2: "...pienso que o sea tanta confianza como para que sea tu intimo no, pero si veo que si hay la confianza y compañerismo necesaria en el trabajo..."

Entrevistado 3: "...si, yo creo que mi equipo es sólido y me apoya siempre..."

Entrevistado 4: "...si me pongo a pensar en otras áreas te diría que no, pero en la mía creo que sí. Nos llevamos bien, compartimos, nos apoyamos, las personas siempre están dispuestas a apoyar y a escucharte..." 
Entrevistado 5: "...no diría que gran compañerismo porque algo que es como cultura dentro de la compañía, es que tu dentro de tu misma área puedes encontrar muchísimo apoyo, pero luego puede pasar con otras áreas que son las que te dicen no, esto es tarea de contabilidad o esto es tarea de sistemas..."

Entrevistado 6: "...Si, siempre nos apoyamos, cuando trabajamos juntos y cuando sale de vacaciones, cubren tu posición y están atentos a que todo marche bien en tu ausencia...."

Entrevistado 7: "...sé que si tengo un problema ellos siempre me van a apoyar..."

Entrevistado 7: "...Si, o sea nos ayudamos cuando no sabemos algo, pero tampoco es que sienta que son mis amigos y que confíe totalmente en ellos..."

Entrevistado 8: "...En algunas ocasiones, porque si cometes un error te señalan y hasta pueden retírate de la empresa. Lo que conlleva a que tienes que tener cero error en todo..."

Entrevistado 9: "...existe bastante compañerismo y respecto al nivel de confianza considero que es intermedio..."

Entrevistado 10: "...Algunas veces hay áreas que se aíslan y solo paran entre ellos, y eso algunas veces te hace pensar que si, les gusta trabajar contigo, o que si les caes o no, pero la mayor parte del tiempo, si he notado que el compañerismo y la confianza predomina en la empresa..."

\section{g) Categoría: Desarrollo Personal}

La mayoría de los participantes perciben que no todos los colaboradores tienen la misma oportunidad para crecer dentro de la empresa, además creen que parte de la opción de crecer está relacionado al interés o ganas de superarse en el ámbito laboral que cada persona tenga.

La mayoría de los participantes cree que tiene opciones para tener un ascenso dentro de la empresa, aunque otros piensan que para crecer deben renunciar o sacar a otras personas. Otro colaborador cree que ya no tiene por donde escalar, ya que ha sido promovido tres veces y no tiene claro por dónde podría seguir creciendo. 
Por otro lado, perciben que no hay las capacitaciones necesarias para poder desarrollarse y si las hay se brindan por favoritismo a otras áreas.

Entrevistado 1: "...no se ah, no estoy muy seguro ah, de echo que algunos tienen mayores facilidades que otros..."

Entrevistado 1: "...ahorita sí creo que yo antes era asistente, analista de tesorería y pase a ser tesorero, pero ahorita si no veo hacia donde..."

Entrevistado 2: "...veo que si están haciendo, este..., están viendo esto... programas, servicios públicos para que la gente se capacite mejor..."

Entrevistado 3: "...sí, creo que siempre se les brinda la capacitación necesaria a todos los empleados. Siempre RRHH realiza un plan de capacitación al año que se debe cumplir..."

Entrevistado 3: "...no todo el personal, básicamente hay funciones que, bueno hay personas en las que sus aspiraciones no van más allá del puesto que tienen..."

Entrevistado 4: "...no creo que todos en realidad, o sea depende pues no?, depende del puesto en el que te desenvuelvas y de lo que hagas..."

Entrevistado 5: "...si, yo creo que sí, de echo me ha pasado, o sea el tiempo que tengo en la empresa siento que he asumido más responsabilidades, tengo mejores beneficios, este ... autoridad también para tomar algunas decisiones..."

Entrevistado 6: "...Así es, si estas capacitado para asumir nuevos retos, te dan esa posibilidad de crecimiento dentro de tu área o en otra de ser el caso...."

Entrevistado 7: "...solo en algunas áreas, digamos a comercial siempre le dan la prioridad..."

Entrevistado 8: "...si tú ves hace tres años los que entraron solo algunos han podido pasar a otro puesto y no todos..."

Entrevistado 9: "...La empresa no invierte en la capacitación necesaria para un desempeño exitoso en comparación a lo que realizan otras empresas..."

Entrevistado 10: "...siento que algunas personas ascienden porque les cae bien al jefe, y las que no, porque según la política no se pueden agregar más personal contratado al organigrama que tiene la empresa..." 


\section{h) Categoría: Agotamiento Emocional}

La mayoría de los participantes se sienten emocionalmente estables y tranquilos, de hecho perciben que el clima laboral ayuda bastante en lo que refiere a sus emociones. Algunos perciben estrés o frustración por momentos, a causa de la carga laboral o de falta de reconocimiento, pero que es algo que está ligado al trabajo y que no es tan grave.

Entrevistado 1: "...de echo que como te digo, ayuda bastante el clima que se maneja..."

Entrevistado 1: "...me siento bien, de echo que siempre hay carga operativa que tienes que hacer, harta chamba, que te toma tiempo y dedicación..."

Entrevistado 2: "... ¿emocionalmente? Tranquila ..."

Entrevistado 3: "...bien, contento, motivado..."

Entrevistado 4: "...me llevo bien con la gente, no tengo mayores problemas con la gente..."

Entrevistado 4: "...claro que a veces me estreso, porque tengo demasiada carga laboral, pero es manejable..."

Entrevistado 5: "...definitivamente hay momento en el día a día en los que, nada te gana un poco la carga laboral y particularmente siento frustración cuando no veo que se cierran todos los temas..."

Entrevistado 5: "...estable..."

Entrevistado 6: "...En el trabajo me siento bien, a veces como en cada mes existen día de presión..."

Entrevistado 7: "...desazón porque no son equitativos..."

Entrevistado 8: "...solo ven errores y no cuando haces o pones tu esfuerzo en tu trabajo..."

Entrevistado 8: "...En muchas ocasiones me apena..."

Entrevistado 9: "...Me siento contenta ..."

Entrevistado 9: "...mi jefe y mi compañero de trabajo contribuyen a que tenga un nivel emocional alto en mi trabajo...." 
Entrevistado 10: "...algunas veces es estresante..."

Entrevistado 10: "...en el tema de ambiente laboral, es grato estar ahí, porque las personas son muy buenas y te ayudan con temas profesionales y también personal..."

\section{i) Categoría: Despersonalización}

La mayoría percibe interés por las personas de su equipo, por las personas que son sus amigos, por la gente que los rodean en el trabajo, pero no sienten interés por otros que no estén en su círculo. Esto puede deberse a la confianza o amistad que puedan tener con las diferentes personas. En cuanto al interés por las cosas que sucedan fuera de la oficina, piensan que lo primero es la familia, que tienen tiempo para ver noticias, pero cuando están trabajando no se enfoquen en esos aspectos, ya que no tienen el tiempo para pensar en eso.

Entrevistado 1: "...si de echo que si me importan, pero siempre con los que tengo mayor química por decirlo así..."

Entrevistado 1: "...primero están las personas más cercanas que son mi familia, mis amigos, que de echo si me importa lo que les pase y siempre estoy pendiente..."

Entrevistado 2: "...la economía me importa bastante, porque tenemos que seguir creciendo como país y nos conviene estar bien para que vengan otras inversiones..."

Entrevistado 3: "...En principio de mi equipo sí, me intereso por ellos y por el resto de las personas, todo depende mucho de si la persona se abre y te cuenta su vida en una conversación..."

Entrevistado 3: "...hay momentos en que la presión te absorbe y tienes que estar concentrado y probablemente en algún momento tus expresiones faciales o verbales puedan demostrar que no te interesa nada..."

Entrevistado 4: "...La verdad, solo me interesa la persona que merece que me interese..." 
Entrevistado 4: "...me importa bastante, ya que leo las noticias, claro que cuando estoy en el trabajo no tengo tiempo ni de pensar en otras cosas...obviamente que si es mi familia hago cualquier cosa, lo que sea por estar pendiente y ayudar..."

Entrevistado 5: "...honestamente cuando estoy en el trabajo de hecho estoy concentrada y enfocada en eso no? No estoy tanto pensando salvo que sea un tema no sé coyuntural o bastante grande o relevante como para enfocarme en eso, después no es como que me la pase viendo las noticias o pensando lo que está pasando en el mundo..."

Entrevistado 6: "...si, me preocupo por cómo se sienten los demás, en su estado anímico y los he apoyado, escuchándolos y aconsejándolos y en la medida de los posible brindándoles mi ayuda..."

Entrevistado 7: "...la sociedad es parte de todos y debemos estar actualizados para mejorarla..."

Entrevistado 8: "...La verdad que no veo mucho noticias, pero trato de leer el comercio los fines de semana..."

Entrevistado 9: "...Principalmente siento interés por las demás personas de mi entorno de trabajo inmediato, por su estado de ánimo y de salud..."

Entrevistado 10: "...Sí de todas maneras, como en todo equipo siempre hay grupos con los que te llevas mucho mejor, con otros mejor, pero en lo personal con las personas que son más apegadas a mí en el trabajo..."

\section{j) Categoría: Realización Personal}

Todos los participantes se sienten felices y tranquilos con lo que están haciendo entorno a su vida laboral, les gusta bastante lo que realizan, ya que son las cosas que quieren hacer. Aunque algunos colaboradores pueden sentir que hacen funciones reiterativas u operativas, además de que piensan que deberían tener una remuneración acorde a sus funciones.

Entrevistado 1: "...si me siento no sé si feliz, pero me siento tranquilo, bien con lo que hago..."

Entrevistado 2: "...si estoy tranquila, porque hago las cosas que quiero hacer..." 
Entrevistado 3: "...si, o sea si bien no es cierto lo que hago es lo que estudie, ehh pero de alguna u otra forma complementa, la forma de la empresa, la forma del trabajo, complementa mucho la formación que tengo y eso me satisface..."

Entrevistado 4: "...o sea feliz creo que no, pero si me gusta lo que hago, me siento tranquila..."

Entrevistado 5: "...si, me gusta bastante lo que hago, este si de echo creo que lo más importante es cuando uno cree en las cosas que hace, es cuando ves los resultados y los cambios..."

Entrevistado 6: "...me gustan las relaciones con mis compañeros, no solo del área sino también con los de otra área, tengo amigos y me siento correspondido por su amistad y sé que mi trabajo también es reconocido..."

Entrevistado 7: "...Solo me siento feliz, porque me gusta lo que hago, solo por eso..."

Entrevistado 8: "...no muchas veces con lo que hago, porque muchas veces te mandan a hacer trabajo que crees ya pasaste esa etapa..."

Entrevistado 9: "...Siento que podría sentirme del todo feliz si mi trabajo sería remunerado acorde con las funciones que realizo, además de que sentiría mayor motivación si hubiera oportunidades de línea de carrera a mediano y largo plazo..."

Entrevistado 10: "...aprendes a amar lo que haces cuando te esfuerza y cuando sabes que puedes dar más de lo tu habías pensado, lo cual te hace sentir realizado..."

En resumen, existen diversas percepciones sobre las 10 categorías expuestas, siendo mayoritarias las respuestas positivas. Goncalves (1997), afirma que el enfoque más eficaz de las definiciones de clima laboral es el que considera que lo esencial es la percepción que tiene el trabajador de las estructuras y de los procesos que hay en una organización.

Por esto, en la categoría de estructura, se encontró que se necesitan documentos formales sobre las funciones que realizan, ya que el no tenerlo puede causar carga 
laboral o que ésta no es equitativa. A pesar de esto, los colaboradores disfrutan lo que hacen, aunque les gustaría tener una remuneración mayor.

Por otro lado en Comunicación y Liderazgo tienen la percepción de que se da de manera horizontal y que los Líderes son participativos. La incidencia de los estilos de liderazgo según Gené y Contel (1999), es bastante fuerte, ya que la forma en que un jefe utiliza su liderazgo, los medios con los que motiva a sus dirigidos, así como los patrones que establece para la interacción con sus subordinados son factores que influyen en la satisfacción laboral de las personas que conforman su equipo.

En la categoría de Realización Personal, los entrevistados expresan que se sienten felices y tranquilos en su puesto de trabajo, creen que el ascenso solo lo recibe la persona que tiene interés en superarse.

Por otro lado, sienten que existe trabajo en equipo, al igual que en la categoría de Despersonalización, donde perciben que si existe interés de parte de los trabajadores hacia sus compañeros de trabajo.

El estrés provoca en el individuo respuestas fisiológicas, afectivas y conductuales, que si se mantienen en el tiempo, terminan alternando su adaptación, adquiriendo el signo de enfermedad (Peiró y Salvador, 1993). Esto no se evidencia en las percepciones de los trabajadores, ya que no existen sentimientos negativos hacia las personas con las que trabajan o hacia el trabajo en sí. Si existieran estas percepciones negativas y perduraran en el tiempo, generaría una serie de consecuencias ya no solo para el profesional, sino para la organización donde desarrolla su trabajo o sus propios compañeros.

Todas están descripciones de las percepciones que tienen los trabajadores sobre el burnout y clima laboral, son información valiosa que debe tener en cuenta el Gerente del área, así como el área de Recursos Humanos. Utilizando de manera eficaz la información, se pueden realizar mejoras en los procesos y también se puede utilizar para mejorar la salud y el ambiente del trabajador.

Como segundo objetivo de esta investigación se planteó identificar cómo están vinculadas las percepciones sobre el clima laboral y burnout de los trabajadores de una empresa privada de Lima Metropolitana. 
Como sostienen Fernández y Paravic (2003), el trabajo juega un papel destacado en la vida del hombre, dado que la mayoría de las personas pasan una tercera parte del día trabajando y lo hacen la mitad de su vida. De esto se desprende la necesidad de establecer cuáles son las condiciones de trabajo, referido a los factores psicosociales que ponen en riesgo la salud de los trabajadores por el surgimiento del síndrome de burnout, del mismo modo es preciso establecer las diferencias existentes entre hombres y mujeres.

Gracias a las percepciones de los trabajadores, se identificó el vínculo que puede existir entre el burnout y el clima Laboral, ya que se tienen opiniones positivas sobre el clima laboral, al igual que los indicadores del burnout, son descritos de manera estable e ideal y no hay aspectos o percepciones negativas sobre el agotamiento emocional, despersonalización o falta de realización personal. Por ejemplo, esto se evidencia en las siguientes oraciones:

"...creo que considero bastante el clima, o sea el ambiente de trabajo es muy bueno, siempre lo he dicho, este de echo que también uno de los factores es que con los que me rodeo, con el entorno con el que trabajo cotidianamente..."

"...me gustan las relaciones con mis compañeros, no solo del área sino también con los de otra área, tengo amigos y me siento correspondido por su amistad y sé que mi trabajo también es reconocido..."

"...En principio de mi equipo sí, me intereso por ellos y por el resto de las personas, todo depende mucho de si la persona se abre y te cuenta su vida en una conversación..."

Al percibir los colaboradores una estructura desorganizada e informal, podría ocasionar una alta carga laboral, ya que no tienen un documento donde se especifiquen sus funciones y responsabilidades del puesto, como por ejemplo lo es una descripción de puesto. Esta carga laboral puede llegar a causar despersonalización o agotamiento emocional, dos de los indicadores de burnout.

Por otro lado, los trabajadores son felices en la empresa, perciben positivamente el ambiente laboral y la cultura. La motivación la perciben como algo económico y el reconocimiento de la empresa hacia el trabajador lo perciben como un impulso para realizar mejor el trabajo. Estás percepciones van de la mano con la percepción de 
realización personal en la que los trabajadores se sienten felices y tranquilos con su vida laboral y profesional. Esto se ve reflejado en las siguientes oraciones:

"... siempre me he sentido a gusto con la gente y con los ideales de la empresa y me he adaptado bien a los cambios..."

"...aprendes a amar lo que haces cuando te esfuerzas y cuando sabes que puedes dar más de lo tu habías pensado, lo cual te hace sentir realizado..."

Se encontraron diferentes percepciones sobre la comunicación, ya que los colaboradores se sienten tranquilos con la forma en la que se comunican los temas en la empresa, pero que falta distribuir mejor la información sobre la misión y visión de la empresa. Por otro lado, algunos colaboradores perciben favoritismo cuando se brinda una idea, ya que a veces no es tomada en cuenta. Esto también se ve reflejado en el indicador de Agotamiento Emocional del burnout, ya que perciben estrés o frustración por no sentirse escuchados o porque no ven sus ideas reflejadas en el trabajo. Esto se evidenció en las siguientes percepciones:

"...Creo que por lo general es horizontal, porque te dan la libertad de comunicarte directamente con tus superiores inmediatos con libertad...."

"...tengo un poco de recelo ya que siento que tiene preferencia con una persona del equipo y siempre conversa con ella, se publican fotos, frases, y eso me incomoda, por eso trato de mantenerme al margen ..."

"...definitivamente hay momento en el día a día en los que, nada te gana un poco la carga laboral y particularmente siento frustración cuando no veo que se cierran todos los temas..."

"...algunas veces es estresante..."

En cuanto a las percepciones que tienen los colaboradores con el liderazgo, sienten que los jefes se están capacitando en temas generales pero que les falta desarrollar otros temas como capacitaciones para inteligencia emocional o manejo de grupos. Además, perciben que solo se fomenta liderazgo para altos mandos y no para mandos medios, causando que no haya línea de carrera establecida por área. Por otro lado, perciben confianza en los líderes, lo que también se percibe en la categoría de Agotamiento emocional, ya que sienten seguridad y compañerismo dentro de la empresa. 
Por otro lado, los colaboradores perciben que la carga laboral no es equitativa, lo que causa que se queden más horas en el trabajo, pero en general perciben que el trabajo no perjudica su tiempo personal. Hay colaboradores que si se sienten agobiados dejando de lado a su familia o vida personal esto se puede ver reflejado en la categoría de Despersonalización, la cual es un indicador de burnout.

Perciben que existe el trabajo en equipo, lo que hace que se sientan apoyados, existiendo compañerismo y confianza, lo cual se puede vincular al indicador de Agotamiento Emocional. Por otro lado, la mayoría de los colaboradores no perciben oportunidades de crecimiento, pero saben que parte de este desarrollo en la empresa depende de cada persona y sus ganas de superarse, esto se ve también en el indicador de realización personal del burnout.

Los trabajadores perciben que no existen capacitaciones necesarias para poder desarrollarse en la empresa y que si existe la posibilidad de tener se elige al área comercial como prioridad. Esto se refleja en la siguiente oración;

"...La empresa no invierte en la capacitación necesaria para un desempeño exitoso en comparación a lo que realizan otras empresas..."

"...solo en algunas áreas, digamos a comercial siempre le dan la prioridad..."

A pesar de las percepciones negativas, que no son muchas, la mayoría de los colaboradores se siente emocionalmente estable, perciben interés por las demás personas de su entorno, son felices y se encuentran tranquilos con su vida laboral.

Como tercer objetivo dentro de esta investigación se planteó: Describir las características de la vinculación existente en las percepciones tanto del clima laboral como del burnout de los trabajadores de una empresa privada de Lima Metropolitana.

En base a los resultados descritos anteriormente, se pudo conocer, que existen varias características tanto del burnout como del clima laboral que son positivas y adecuadas para el trabajador, como por ejemplo, en la categoría de Despersonalización de burnout, uno de los entrevistados dice: "...Principalmente siento interés por las demás personas de mi entorno de trabajo inmediato, por su estado de ánimo y de salud...", así como, en la categoría de compañerismo y confianza un entrevistado dice : "...existe bastante compañerismo y respecto al nivel de confianza considero que es 
intermedio...", lo que conlleva a que existan buenas percepciones sobre el clima laboral y sobre el indicador de Burnout.

Además en varias citaciones los participantes dan énfasis al buen clima laboral que se maneja en la empresa, a lo bien que se sienten emocionalmente, al sentimiento de felicidad con respecto a su puesto de trabajo, a estar felices por las funciones que realizan y con el puesto que tienen actualmente, al igual que a la importancia sobre el sentimiento de interés por las demás personas. Por ejemplo, un entrevistado piensa: "...el ambiente laboral es muy grato y se preocupan por el bienestar de los trabajadores cosa que en la mayoría de empresas no se encuentra...".

De acuerdo con Goncalves, el conocimiento del clima organizacional proporciona retroinformación acerca de los procesos que determinan los comportamientos organizacionales, permitiendo, además, introducir cambios planificados tanto en las actitudes y conductas de los miembros, como en la estructura organizacional o en uno o más de los subsistemas que la componen. La importancia de esta información se basa en la comprobación de que el clima organizacional influye en el comportamiento observable de los trabajadores a través de percepciones estabilizadas que filtran la realidad y condicionan los niveles de motivación laboral y rendimiento entre otros (como se citó en Marchant, 2005, p. 134).

Es por esto que el clima laboral y el burnout son factores que van de la mano. Son importantes en la producción y rendimiento de las empresas, al igual que son el motor y motivación de los trabajadores. Las percepciones de los dos constructos son bien parecidas en cuanto a lo positivo y negativo que describen los colaboradores, las características de la vinculación de estas percepciones se puede observar por las respuestas que brindan los entrevistados sobre los sentimientos que tienen sobre la empresa y sus vidas.

En conclusión, este estudio es una herramienta que puede ser utilizada por el área de Recursos Humanos, para mejorar el clima laboral, usando como base las percepciones de los trabajadores. En este sentido el trabajo de investigación que se realizó se reviste de importancia al describir los indicadores de clima laboral y burnout, ya que con esto se puede observar como las percepciones afectan a las funciones y a las tareas que los trabajadores desempeñan todos los días en sus puestos de trabajo dentro de la empresa. 
Este estudio también brinda un panorama para la realización de planes de acción de clima laboral, la información recolectada es importante, ya que el clima organizacional influye en el comportamiento de los colaboradores, a través de percepciones que filtran la realidad y condicionan los niveles de motivación laboral y rendimiento profesional.

Por otro lado, el conocimiento aportado con la presente investigación ha aumentado las posibilidades de que el personal de Recursos Humanos de la empresa realice acciones por cada categoría realizada, ya que tiene información sobre las percepciones y sentimientos de los colaboradores de la empresa. Por ejemplo, se puede destinar un presupuesto de capacitación por áreas para luego tener reuniones con el gerente de cada división y abarcar una capacitación en el año para cada colaborador.

Otra acción puede ser entregar la descripción de puesto a cada colaborador y líder, para alinear los objetivos de los colaboradores con la estrategia de la empresa. 


\section{CAPÍTULO VI: CONCLUSIONES}

- Los trabajadores perciben una estructura informal y desorganizada, donde las funciones y objetivos de cada puesto no están bien definidos, realizándose en base a las necesidades inmediatas, generando sobrecarga laboral. Las descripciones del puesto son importantes para un correcto desarrollo de las políticas de recursos humanos, también ayuda a maximizar el desempeño y la productividad del mismo. Una descripción correcta del puesto de trabajo ayuda a determinar qué factores harán que el desempeño del mismo sea eficaz.

- Los trabajadores observan el ambiente laboral y la cultura de la empresa de manera positiva, a pesar de percibir la estructura desorganizada, lo que ayuda a que sientan satisfacción con la empresa, por otro lado, se sienten a gusto en su puesto de trabajo, ya que se sienten motivados con los retos y por sus propias aptitudes buscan lograr un buen desempeño.

- Los trabajadores perciben que la comunicación dentro de la empresa es horizontal, aunque en algunos casos por el tipo de información se da de manera vertical. La información sobre la empresa se está reforzando poco a poco para que llegue a todos los colaboradores, a pesar de que los jefes saben escuchar y tener conversaciones de manera fluida con todo el personal.

- Los trabajadores destacan que el liderazgo no se fomenta dentro de la empresa y por lo tanto los líderes no están totalmente capacitados. Por otro lado, el estilo de liderazgo que se maneja en la empresa es participativo, donde el líder está comprometido con la empresa y siempre brinda información necesaria cuando se necesita. Al fomentar el liderazgo a todo nivel, Recursos Humanos puede identificar y desarrollar de manera más proactiva a los posibles sucesores de los líderes. Así como también, colaboradores preparados y motivados para enfrentar nuevos retos.

- Los trabajadores opinan que la carga de trabajo no está distribuida equitativamente, ya que el día a día brinda nuevas tareas y funciones que se deben realizar. Pero, eso no influye en su vida personal, ya que la empresa es flexible ante las necesidades personales que puedan tener los colaboradores. 
- Los trabajadores divisan que existe trabajo en equipo dentro de su área y no en toda la empresa. Se puede resaltar el apoyo que tienen de sus compañeros y el compañerismo que se genera por el clima laboral, lo que les genera bienestar.

- Los trabajadores perciben que existe la posibilidad de crecimiento profesional dentro de la empresa, aunque se puede ver limitada por la falta de comunicación de la línea de carrera por puestos, como de la falta de capacitación y del interés que brinde cada trabajador.

- Los trabajadores no perciben agotamiento emocional, a pesar de que por momentos la carga laboral produzca estrés y porque ello no es continuo, por lo que no genera agotamiento.

- No se identificaron indicadores de despersonalización, ya que sienten interés por las demás personas del entorno, como su familia, estando al tanto por los sucesos del entrono aunque cuando están laborando sienten que están tan concentrados en su labor que no se enfocan en lo que sucede fuera del trabajo.

- Los trabajadores se sienten realizados personalmente, ya que perciben su vida laboral de manera positiva, con entusiasmo, tranquilidad y reconocimiento, aunque algunos no se consideran bien remunerados.

- Se identificó una vinculación a partir de las percepciones de los trabajadores sobre el clima laboral y burnout, ya que las percepciones de los trabajadores demuestran que existe un ambiente de trabajo positivo y tranquilo, sin demostrar percepciones que puedan significar síntomas de padecer burnout.

- Las percepciones del clima laboral como del burnout se vinculan en las respuestas de los entrevistados, dando como resultado opiniones favorables sobre los dos fenómenos, así como percepciones negativas en algunos casos. Las respuestas en varias ocasiones tienen sentimientos relacionados a los dos fenómenos.

- La investigación presente aporta información significativa que los profesionales de Recursos Humanos deben tener en cuenta para promover soluciones que permitan modificar las percepciones negativas de los colaboradores del área de Administración y Finanzas, así como reforzar las positivas. 


\section{CAPÍTULO VII: RECOMENDACIONES}

A continuación, se presentan las recomendaciones para tanto para futuras investigaciones sobre el tema como para el personal del área de Recursos Humanos:

- Realizar organigramas y descripciones de puesto donde se puedan definir las funciones y objetivos para que no exista sobrecarga de trabajo. Tener Organigramas ayuda al personal de Recursos Humanos a entender la labor de cada trabajador y así poder crear una línea de carrera por área. Además las descripciones del puesto permiten la valoración del mismo, la selección de la persona idónea y la posibilidad de evaluar el desempeño de la persona que desarrolla un puesto de trabajo determinado.

- Fomentar el liderazgo en todo nivel, así como realizar capacitaciones constantes para los líderes. Se debe generar una cultura de Liderazgo en la empresa, donde todos los colaboradores compartan la responsabilidad de la misión de la empresa.

- Integrar las áreas de la empresa con capacitaciones o dinámicas para que interactúan todos los trabajadores sin importar cuáles son sus funciones o a qué división pertenecen. Este punto, puede ayudar a realizar las tareas de manera más eficiente, ya que al conocerse todos, es más fácil que pregunten o encuentren una solución más rápidamente.

- Diseñar una línea de carrera por áreas, para brindar seguridad y una visión de crecimiento dentro de la empresa, al igual que Planes de Desarrollo para todos los colaboradores. El plan de desarrollo y línea de carrera servirán para planear las necesidades futuras que la empresa pueda tener a nivel de talento. Al establecer líneas de carrera para ciertas posiciones estratégicas de la empresa, los colaboradores tienen más clara la dirección de su crecimiento.

- Brindar mayor capacitación para que los trabajadores sientan confianza y compromiso con su trabajo y la empresa. Además, tener colaboradores capacitados ayuda a la productividad y rentabilidad de la empresa. 
- Hacer una investigación sobre las remuneraciones según el puesto de trabajo en el mercado actual, sobre todo para el área de Administración y Finanzas. Esta investigación se puede realizar con consultores especializadas que comparan por rubro, área, puesto, etc.

- Analizar las percepciones negativas y así poder realizar planes de acción individuales y por áreas.

- Realizar un estudio cualitativo y cuantitativo de clima laboral que permita tener una visión integral de los constructos. 


\section{REFERENCIAS}

Alfaro, R., Leyton, S., Meza, A y Sáenz, I. (2012). Satisfacción laboral y su relación con algunas variables ocupacionales en tres municipalidades (Tesis de Maestría). Pontificia Universidad Católica del Perú, Lima, Perú. Recuperada de: http://tesis.pucp.edu.pe/repositorio/bitstream/handle/123456789/4593/ALFARO _LEYTON_MEZA_SAENZ_SATISFACCION_LABORAL.pdf?sequence=1

Apiquian, A. (22 de Octubre de 2007). El Síndrome del Burnout en las Empresas. Recuperado de http://www.anahuac.mx/psicologia/

Arbaiza, L. (2010). Comportamiento organizacional: bases y fundamentos. Buenos Aires: Cengage Learning.

Bianchi, F. (1190). El estrés y la enfermería: análisis de la actuación de la enfermera de la sala de operaciones (Tesis de Licenciatura). Universidad de San Pablo, Sao Paulo, Brasil. Recuperada de http://bases.bireme.br/cgibin/wxislind.exe/iah/online/?IsisScript=iah/iah.xis\&src=google \&base=BDENF \&lang=p\&nextAction=lnk\&exprSearch=5801\&indexSearch=ID

Bosqued, M. (2008). Quemados: El síndrome del Burnout ¿Qué es y cómo superarlo? Barcelona: Paidós Ibérica.

Brunet, L. (2004). El clima de trabajo en las organizaciones. México: Trillas.

Campuzano, J. y Álvarez, A. (2010). Síndrome de Burnout y su relación con el clima y la motivación laboral en los trabajadores de Sonigas S.A. de C.V Planta Tres Marias. Comunicación presentada en el 3er. Foro de las Américas en Investigación sobre Factores Psicosociales, Estrés y Salud Mental en el Trabajo, 14-16 de Octubre. Lima: Instituto Nacional de Salud Pública. Recuperado de http://www.factorespsicosociales.com/tercerforo/posters/documentos/C09.pdf

Caligiore, I. y Díaz, J. (2003). Clima organizacional y desempeño de los docentes en la ULA: Estudio de un caso. Revicyhluz, Revista Venezolana de Gerencia, 8(24), 118.

Casas, S. y Klijn, T. (2006). Promoción de la salud y su entorno laboral saludable. Revista Latino Americana de Enfermage, 14(1), 136-41.

Cherniss, C. (1982). Job stress and burnout. Beverly Hills: Sage.

Crespín, A. (2012). Clima Organizacional según la percepción de los docentes de una Institución educativa de la región Callao (Tesis de Maestría). Universidad San Ignacio de Loyola, Callao, Perú. Recuperada de http://repositorio.usil.edu.pe/wpcontent/uploads/2014/07/2012_Cresp\%C3\%ADn_Clima-organizacional- 
seg\%C3\%BAn-la-percepci\%C3\%B3n-de-los-docentes-de-unainstituci\%C3\%B3n-educativa-de-la-Regi\%C3\%B3n-Callao.pdf

Creswell, J. (2005). Educational Research: planning, Conducting and evaluating quantitative and qualitative research. Upper Saddle River: Pearson Education.

Daltsmalchian, A., Adamson, R. y Blyton, P. (1986). Developing a measure of industrial relations climate. Industrial relations, 41, 851-859.

Dávila, J. y Romero, P. (2010). Relación entre el síndrome del burnout y la percepción sobre el clima organizacional en médicos del área de emergencia (Tesis de Licenciatura). Universidad Católica Andrés Bello, caracas, Venezuela. Recuperada de http://biblioteca2.ucab.edu.ve/anexos/biblioteca/marc/texto/AAR5044.pdf

Dávila, M. (2011). Clima organizacional y síndrome de burnout en una empresa mediana de manufactura (Tesis de Maestría). Tecnológico de Estudios Superiores de Coacalco, Coacalco de Berriozábal, México. Recuperada de http://www.tesco.edu.mx/gem/DOC/PDF/publicaciones/tescoatl/tesco_pdf_tesco at132_4_climaOrganizacionalSindromeBurnot.pdf

Díaz, S. (Setiembre, 2013). Satisfacción laboral y síndrome de burnout entre el personal de un policlínico y en el de una comunidad local de administración de salud, distrito la victoria, Chiclayo - 2012 (Tesis de Licenciatura).Universidad Católica Santo Toribio de Mogrovejo, Chiclayo, Perú. Recuperado de: http://tesis.usat.edu.pe/jspui/bitstream/123456789/328/1/TL_D\%C3\%ADaz_Rui z_StephanyMedalit.pdf

Durkheim, E. (1924). Educación y Sociología. Madrid: De la lectura.

Escobar - Pérez, J. y Cuervo - Martinez, A. (2008). Validez de Contenido y Juicio de Expertos: Una Aproximación a su Utilización. Avances en Medición, (6), 27-36.

Farber, B. (1991). Crisis in education:stress and burnout in the American teacher. San Francisco: Jossey - bass.

Fernández, B. y Paravic, T. (2003). Nivel de satisfacción laboral en enfermeras de hospitales públicos y privados de la provincia de Concepción, Chile. Revista Ciencia y Enfermería, 9(2), 57-66.

Fidias, A. (2012). El Proyecto de Investigación. Introducción a la Metodología Científica (6 ${ }^{\mathrm{a}}$ Ed.). Caracas: Episteme.

Forehand, G. y Gilmer, B. (1964). Environmental variations in studies of organizational climate. Psychological Bulletin, (6), 361-382.

Galeano, M. (2004). Diseño de proyectos de investigación cualitativa. Medellin: Fondo editorial universidad AFIT.

Galeano,L., Bromet, D. y Galvis, S. (2012). El síndrome de Burnout y el clima 
organizacional en el desarrollo laboral. Universidad de San Buenaventura

Medellín.

Recuperado

de

http://bibliotecadigital.usb.edu.co/jspui/handle/10819/1056

Gellerman, S. (1960). People, problems and profits. New York: McGraw-Hill

Gene, J. y Contel, J.C. (1999). Gestión en atención primaria; Incorporación de la Práctica Directiva en el Liderazgo Asistencial. Barcelona: Masson S.A. Recuperado

de https://pirhua.udep.edu.pe/bitstream/handle/123456789/2285/MAE_EDUC_140. pdf? sequence $=1$

Gibbs, G. (2012). El análisis de datos cualitativos en investigación cualitativa. Madrid: Morata.

Gilbert, S., Laschinger, H. K. S. y Leiter, M. (2010). The mediating effect of burnout on the relationship between structural empowerment and organizational citizenship behaviours. Journal of Nursing Management, 18(3), 339-348. Recuperado de http://dx.doi. org/10.1111/j.1365-2834.2010.01074.x

Gil-Monte, P. R., y Peiró, J. M. (1997). Desgaste psíquico en el trabajo: El síndrome de quemarse. Madrid: Síntesis.

Gil-Monte, P. (2003). Burnout syndrome: ¿Síndrome de quemarse en el trabajo, desgaste profesional, estrés laboral o enfermedad de Tomás? Revista de Psicología del trabajo y las organizaciones, (2), 19.

Gil-Monte, P. (2005). El Síndrome de quemarse por el trabajo: Burnout: una enfermedad laboral en la sociedad del bienestar. Madrid: Pirámide.

Goncalves, A. (1997). Dimensiones del Clima Organizacional. Recuperado de: www.qualidade.org/articles/dec $97 / \mathrm{html}$

Grau J., Vallejo, R. y Tomás, E. (2004). El burnout y las manifestaciones psicosomáticas como consecuentes del clima organizacional y de la motivación laboral. Psicothema, 125-131. Recuperado de http://156.35.33.98/reunido/index.php/PST/article/view/8198/8062

Guzmán, L. y Guzmán, M. (2010). Factores asociados al síndrome de burnout en el personal de enfermería del Hospital Militar Central. Revista científica de la Universidad Peruana de Integración Global, 1(1), 32-27.

Hartog - Cuentas, M. (2015). Percepción de los Docentes respecto del Clima Laboral en la Institución educativa privada Santa Margarita - Surco - Lima. Universidad de Piura, Perú. Recuperado de: http://pirhua.udep.edu.pe/bitstream/handle/123456789/2285/MAE_EDUC_140. pdf? sequence $=1$

Hernández, A. (1991). La Investigación-Acción Participativa y la Producción de 
Conocimientos. Revista de Faces de la Universidad de Carabobo, 67-115.

Heidegger, M. (2006). Introducción a la fenomenología de la religión. México DF: Fondo de Cultura Económica.

Hernández, S. R., Fernández, C. C. y Baptista, L. P. (2014). Metodología de la investigación. México D.F.: McGraw-Hill Education.

Hidalgo, M. y Moreno, M. (2010). Relación entre el clima organizacional y el síndrome de burnout en empleados de una firma de vigilancia en una empresa carbonera de la Guajira. Revista Psicogente, 292-305. Recuperado de http://www.imbiomed.com.mx/1/1/articulos.php?method=showDetail\&id_revist $\mathrm{a}=283$ \&id_seccion $=4427 \&$ id_ejemplar $=7385 \&$ id_articulo $=74059$

Husserl, E. (1998). Invitación a la fenomenología. Barcelona: Paidós.

Iriondo, J. (2007). Desarrollo de la Cultura Organizacional. Recuperado de http://www.gestiopolis.com/desarrollo-de-la-cultura-organizacional/

Krueger R. y Casey M. (2000). A practical guide for applied research (3th edition). Thousand Oaks CA: Sage.

Kvale, S. (1996). InterViews-An introduction to qualitative research interviewing. Thousand Oaks, CA: Sage.

Kvale, S. (2008). Las Entrevistas en Investigación Cualitativa. Madrid: Morata.

Leiter, M., y Maslach, C. (1988). The impact of interpersonal enviroment on burnout and organizational commitment. Journal of Occupational Behavior, 9, 297- 308.

Litwin, G. y Stringer, R. (1968). Motivation and Organizational Climate. Boston: Division of Research, Graduate School of Business Administration, Harvard University.

Lluch, M. T. (2004). Enfermería Psicosocial y de Salud Mental; Marco Conceptual y Metodológico. Barcelona: Universidad de Barcelona.

Maish, E. (2004). Pautas para realizar estudios de clima organizacional. Revistas de Investigación UNMSM, 7(13), 88-90. Resumen recuperado de http://revistasinvestigacion.unmsm.edu.pe/index.php/administrativas/article/vie w/9859

Marchant, L. (2005). Hacia un Modelo de Implementación del Alineamiento Estratégico: Actualizaciones para el Desarrollo Organizacional. Universidad Viña del Mar, Viña del Mar, Chile.

Martínez, M. (2006). La investigación cualitativa (Síntesis Conceptual). Revista IIPSI, Universidad Nacional Mayor de San Marcos, 9(1), 123-146.

Maslach, C. y Jackson, S. (1981). The measurement of experienced burnout. Journal of Occupational Behavior, (2), 99-113. 
Maslach, C., Schaufeli, W. y Leiter, M. (1981). Job burnout. Annual Review Psychology, (52), 397-422.

Mingote-Adán, J. C. (1998). Síndrome de burnout o síndrome de desgaste profesional. Formación Médica Continuada en Atención Primaria, 5(8), 493-508.

Morales, F., Huici, C., Moya, M., Gaviria, E., López, M. y Nouvilas, E. (1999). Psicología social. Madrid: McGraw-Hill Interamericana.

Morse, J. (1995). The significance of saturation. Qualitative Health Research, 5(2), 147-149.

Núñez, L. (2010). El síndrome de quemarse por el trabajo (SQT) en el profesorado de una zona andina del Perú: informe de investigación. Recuperado de http://dide.minedu.gob.pe/xmlui/handle/123456789/791

Ocampo, M. (2007). Comunicación empresarial (1a Ed.). Bogotá: Universidad de la Sabana.

Ocampo, M. (2007). Humanizar la comunicación, la mejor apuesta de la organización. Bogotá: ECOE.

Patton, M. (1990). Qualitative evaluation and research methods. (2nd. Ed.). Newbury Park, CA: Sage.

Peiró, J. y Salvador, A. (1993). Control del estrés laboral. Madrid: Eudema

Pérez, N. y Rivera, P. (2015). Clima organizacional y satisfacción laboral en los trabajadores del instituto de investigaciones de la Amazonía peruana, período 2013 (Tesis de Maestría).Universidad Nacional de la Amazonía peruana, Iquitos, Perú. Recuperado de: http://dspace.unapiquitos.edu.pe/bitstream/unapiquitos/363/1/maestria.pdf

Pineda, B., De Alvarado, E., y De Canales, F. (1994). Metodología de la investigación, manual para el desarrollo de personal de salud (2a ed.). Washington: Organización Panamericana de la Salud.

Pines, A., y ARONSON, E. (1988). Career burnout: causes and cures. New York: The Free Press.

Reaño, N., y Campos, M. (2012). Cuidado enfermero desde la percepción de la persona hospitalizada en el servicio de cardiología del HNAAA- Chiclayo 2012 (Tesis para obtener el grado de Maestría). Universidad Católica Santo Toribio De Mogrovejo, Chiclayo, Perú. Recuperado de http://tesis.usat.edu.pe/jspui/bitstream/123456789/270/1/TL_Rea\%C3\%B1oVas quezNuria_CamposFigueroaMarcia.pdf

Rodríguez, G., Gil, J. y García, E. (1996). Metodología de la Investigación Cualitativa. Málaga: Aljibe 
Rodríguez, A. A., Retamal, M. P., Lizana, J. N. y Cornejo, F. A. (2008). Clima y satisfacción como predictores del desempeño: evaluación en una empresa pública chilena (CEPA). Facultad de Psicología de la Universidad de Talca, Talca, Chile. Recuperado de http://www.cepa.utalca.cl/Pdf/Reodriguez_et\%20al_2008.pdf

Rothbart, M., y Park, B. (1986). On the confirmability and disconfirmability of trait concepts. Journal of Personality and Social Psychology, 50, 131-142.

Ruiz, J. I. (2012). Metodología de la investigación cualitativa. Bilbao: Universidad de Deusto.

Salamanca, A. y Martín - Crespo, C. (2007). El Muestreo en la Investigación Cualitativa. Departamento de Investigación de FUDEN: Nure Investigación.

Salazar, R., Leyton, S., Meza, A. y Sáenz, I. (2012). Satisfacción laboral y su relación con algunas variables ocupacionales en tres municipalidades (Tesis para obtener el grado de Maestría). Pontificia Universidad Católica del Perú, Lima, Perú. Recuperado de: http://tesis.pucp.edu.pe/repositorio/bitstream/handle/123456789/4593/ALFARO _LELEYT_MEZA_SAENZ_SATISFACCION_LABORAL.pdf?sequence=1\&is Allowei=y

Shirom, A. (1989). Burnout in work organizations. New York: John Wiley and Sons.

Silva, M. (1996). El clima en las organizaciones. Barcelona: EUB

Villa, A. y Villar, L.M. (1992). Clima organizativo y de aula. Teorías, modelos e instrumentos de medida. Vitoria: Gobierno Vasco.

Villacís, S. (2015). Relación del síndrome de burnout y el clima organizacional. Ecuador: Pontificia Universidad Católica de Ecuador. Recuperado de: http://repositorio.pucesa.edu.ec/jspui/bitstream/123456789/1094/1/75646.pdf

Villamil, O., Sánchez, W., Paredes, J. y Pineda, O. (2012). Influencia del clima organizacional sobre la Satisfacción laboral en los empleados de la Municipalidad de Choloma. San Pedro Sula, Honduras: Unitec.

Vásquez, J., Maruy, A. y Verne, E. (2014). Frecuencia del síndrome de burnout y niveles de sus dimensiones en el personal de salud del servicio de emergencia de pediatría del Hospital Nacional Cayetano Heredia en el año 2014. Lima, Perú. Recuperado de: http://www.scielo.org.pe/pdf/rnp/v77n3/a05v77n3.pdf

Vizcarra, M., Llaja, V. y Talavera, J. (2015). Clima laboral, burnout y perfil de personalidad: un estudio en personal asistencial de un hospital público en Lima. Informes Psicológicos, 15(2), 111- 126. Recuperado de: http://dx.doi. org/10.18566/infpsicv15n2a06 
ANEXOS 


\section{ANEXO 1: Guía de Entrevista semiestructurada}

\section{Clima Laboral}

- Estructura organizacional.

¿Las responsabilidades y objetivos de cada uno de los puestos de trabajo, están claramente definidos y registrados en documentos formales?

¿Sientes que tus funciones y labores son mayores que las de tus pares? ¿Es justo como están divididas las funciones?

- Satisfacción con la empresa y el trabajo desempeña.

¿Trabajas a gusto, disfrutas las funciones que realizas?

¿Te sientes motivado con lo que haces? ¿Por qué?

¿Te siente a gusto con la empresa donde trabajas?

- Comunicación.

¿Cómo es el flujo de comunicación en la empresa (ascendente, descendente, horizontal)?

¿Crees que se comunican adecuadamente los planes, los objetivos, la misión, la visión y los valores organizacionales?

¿Sientes que te escuchan cuando das tu opinión o ideas?

¿La comunicación que tienes con tu jefe es fluida? ¿Te escucha?

\section{- Liderazgo.}

¿Se fomenta el liderazgo a todo nivel en la empresa? ¿Cómo es ese estilo de Liderazgo? ¿Estás conforme con el estilo de liderazgo que se practica en la empresa? 
¿Sientes que los líderes están capacitados? ¿Existe una relación cercana con ellos?

- Carga de trabajo.

¿Sientes que el trabajo es repartido equitativamente entre todas las áreas?

¿Terminas tu carga laboral en el horario establecido de trabajo?

¿Sientes que tienes mucho trabajo y no te alcanza para tu vida personal?

- Trabajo en equipo.

¿Consideras que puedes contar con tu equipo de trabajo para resolver cualquier problema?

¿Entre los miembros de los equipos de trabajo de la empresa existe un gran compañerismo y confianza?

¿Te sientes apoyado por tu equipo de trabajo?

- Capacitación y desarrollo personal.

¿Todo el personal tiene posibilidades de crecimiento dentro de la empresa?

¿La empresa brinda la capacitación necesaria para un desempeño exitoso de los puestos?

¿Crees que puedas crecer dentro de la empresa? ¿Por qué?

\section{Burnout}

- Agotamiento Emocional

¿Cómo te sientes emocionalmente en tu trabajo?

- Despersonalización

¿Sientes interés por las demás personas? ¿Te importa lo que pasa fuera del trabajo? 


\section{- Realización Personal}

¿Te sientes feliz en tu trabajo? ¿Te gusta lo que haces? 


\section{ANEXO 2: Libro de Códigos}

\begin{tabular}{|c|c|}
\hline CATEGORIA 1 & Estructura \\
\hline Sub - Categoría 1.1 & Funciones \\
\hline Sub - Categoría 1.2 & Objetivos \\
\hline Sub - Categoría 1.3 & Carga laboral \\
\hline & 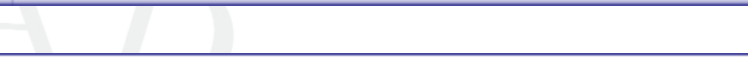 \\
\hline CATEGORÍA 2 & $\begin{array}{l}\text { Satisfacción con la empresa y el } \\
\text { puesto }\end{array}$ \\
\hline Sub - Categoria 2.1 & Puesto de trabajo \\
\hline Sub - Categoría 2.2 & Ambiente de trabajo \\
\hline Sub - Categoría 2.3 & Funciones \\
\hline Sub - Categoría 2.4 & Motivación \\
\hline & 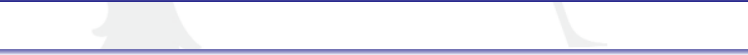 \\
\hline CATEGORÍA 3 & Comunicación \\
\hline Sub - Categoria 3.1 & Flujo \\
\hline Sub - Categoría 3.2 & Escucha \\
\hline Sub - Categoria 3.3 & Comunicación con jefe \\
\hline Sub - Categoría 3.4 & $\begin{array}{l}\text { Comunicación sobre información de la } \\
\text { empresa }\end{array}$ \\
\hline & 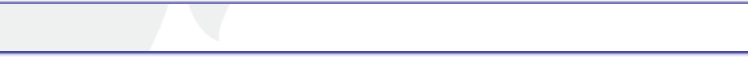 \\
\hline CATEGORÍA 4 & Liderazgo \\
\hline Sub - Categoria 4.1 & Líderes capacitados \\
\hline Sub - Categoría 4.2 & Fomentar liderazgo \\
\hline Sub - Categoria 4.3 & Estilo de liderazgo \\
\hline Sub - Categoria 4.4 & Relación con líderes \\
\hline & 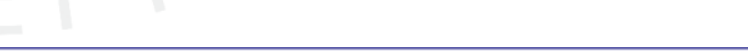 \\
\hline CATEGORÍA 5 & Carga de trabajo \\
\hline Sub - Categoría 5.1 & División de funciones \\
\hline Sub - Categoría 5.2 & Horario de trabajo \\
\hline Sub - Categoría 5.3 & Tiempo personal \\
\hline
\end{tabular}




\begin{tabular}{|c|c|}
\hline CATEGORÍA 6 & Trabajo en equipo \\
\hline Sub - Categoría 6.1 & Resolución de problemas \\
\hline Sub - Categoría 6.2 & Compañerismo y confianza \\
\hline Sub - Categoría 6.3 & Apoyo \\
\hline CATEGORÍA 7 & Desarrollo personal \\
\hline Sub - Categoria 7.1 & Oportunidades de crecimiento \\
\hline Sub - Categoría 7.2 & Capacitaciones \\
\hline Sub - Categoría 7.3 & Ascenso \\
\hline & 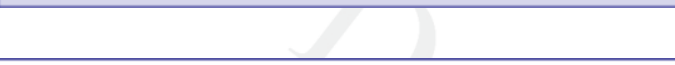 \\
\hline CATEGORÍA 8 & Agotamiento emocional \\
\hline Sub - Categoria 8.1 & Clima laboral \\
\hline Sub - Categoria 8.2 & Carga de trabajo \\
\hline Sub - Categoria 8.3 & Emociones \\
\hline & 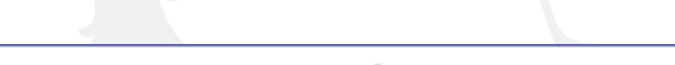 \\
\hline CATEGORÍA 9 & Despersonalización \\
\hline Sub - Categoría 9.1 & $\begin{array}{l}\text { Interés por las personas que te } \\
\text { rodean }\end{array}$ \\
\hline Sub - Categoría 9.2 & $\begin{array}{l}\text { Interés por situaciones externas no } \\
\text { laborales }\end{array}$ \\
\hline E & 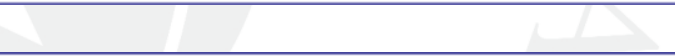 \\
\hline CATEGORÍA 10 & Realización personal \\
\hline Sub - Categoría 10.1 & Felicidad con tu profesión \\
\hline Sub - Categoría 10.2 & Felicidad con el puesto \\
\hline
\end{tabular}




\section{ANEXO 3: Categorización}

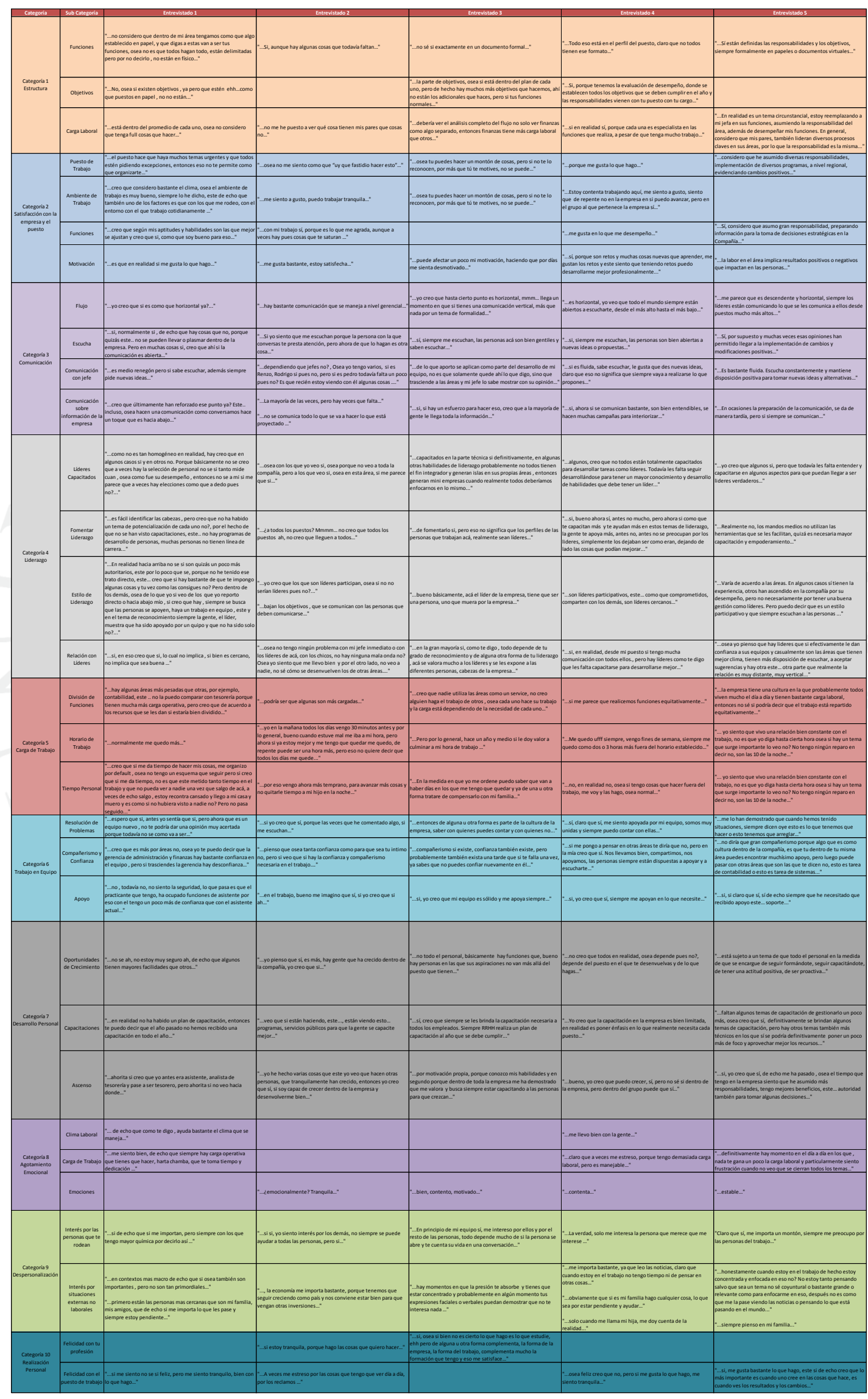




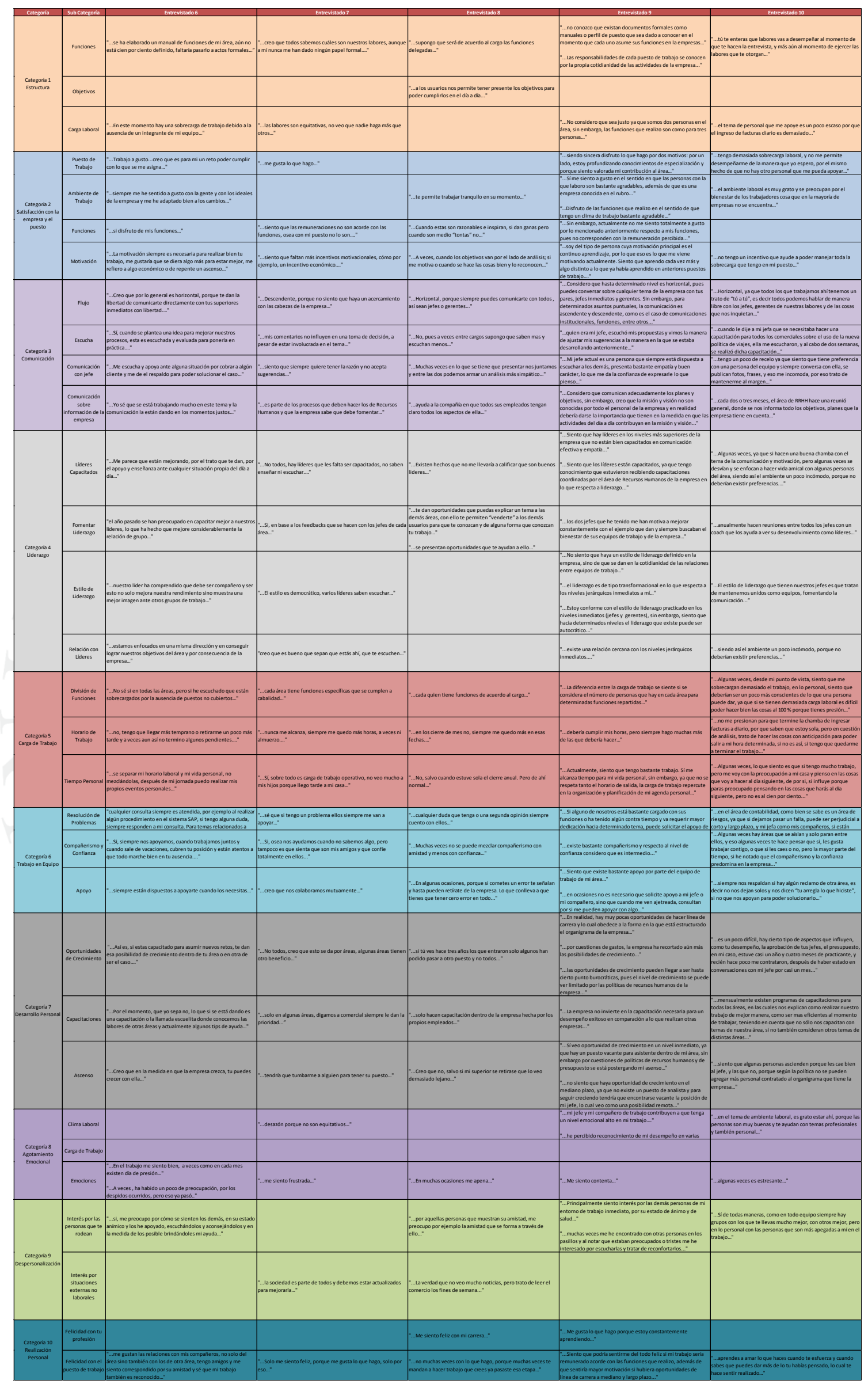




\section{ANEXO 4: Consentimiento Informado}

\section{FICHA DE CONSENTIMIENTO}

El propósito de esta ficha de consentimiento es proveer al participante en esta investigación una clara explicación de la naturaleza de la misma, así como de su rol en ella como participante.

La presente investigación es conducida por Ximena Pesaque, de la Universidad De Lima. La meta de este describir las percepciones de los trabajadores sobre los indicadores del síndrome de Burnout y clima laboral en una empresa privada de Lima Metropolitana, identificar cómo están vinculadas las percepciones sobre el Clima Laboral y Burnout de los trabajadores de una empresa Privada de Lima Metropolitana y describir las características de la vinculación existente a partir de las percepciones de los trabajadores de una empresa Privada de Lima Metropolitana sobre el Clima Laboral y Burnout.

Si usted accede a participar en este estudio, se le pedirá tener una entrevista corta y llenar una ficha de datos. Esto tomará aproximadamente una hora de su tiempo.

La participación es este estudio es estrictamente voluntaria. La información que se recoja será confidencial y no se usará para ningún otro propósito fuera de los de esta investigación. Sus respuestas a las preguntas de la encuesta y a la ficha de datos serán codificadas usando un número de identificación y por lo tanto, serán anónimas.

Si tiene alguna duda sobre este proyecto, puede hacer preguntas en cualquier momento durante su participación en él. Igualmente, puede retirarse del mismo en cualquier momento sin que eso lo perjudique en ninguna forma. Si alguna de las preguntas le parecen incómodas, tiene usted el derecho de hacérselo saber al investigador o de no responderlas.

Desde ya le agradecemos su participación.

Acepto participar voluntariamente en esta investigación, conducida por la persona Ximena Pesaque, de la carrera de Psicología, de la Universidad de Lima. He sido 
informado (a) de que la meta de este estudio es describir las percepciones de los trabajadores sobre los indicadores del síndrome de Burnout y clima laboral en una empresa privada de Lima Metropolitana, identificar cómo están vinculadas las percepciones sobre el Clima Laboral y Burnout de los trabajadores de una empresa Privada de Lima Metropolitana y describir las características de la vinculación existente a partir de las percepciones de los trabajadores de una empresa Privada de Lima Metropolitana sobre el Clima Laboral y Burnout.

Me han indicado también que tendré que responder una ficha de datos y una entrevista, lo cual tomará aproximadamente una hora.

Reconozco que la información que yo provea en el curso de esta investigación es estrictamente confidencial y no será usada para ningún otro propósito fuera de los de este estudio sin mi consentimiento. He sido informado de que puedo hacer preguntas sobre el proyecto en cualquier momento y que puedo retirarme del mismo cuando así lo decida, sin que esto acarree perjuicio alguno para mi persona. De tener preguntas sobre mi participación en este estudio, puedo contactar a Ximena Pesaque al teléfono 946599363.

Entiendo que una copia de esta ficha de consentimiento me será entregada, y que puedo pedir información sobre los resultados de este estudio cuando éste haya concluido. Para esto, puedo contactar a Ximena Pesaque al teléfono anteriormente mencionado. 